\title{
ANALÍTICA E ONTOLOGIA: SOBRE A TEORIA KANTIANA DOS OBJETOS*
}

\author{
[ANALYTIC AND ONTOLOGY: \\ ON THE KANTIAN THEORY OF OBJECTS]
}

Juan Adolfo Bonaccini

(1965-2016)

Natal, v. 23, n. 41

Maio-Ago. 2016, p. 295-346

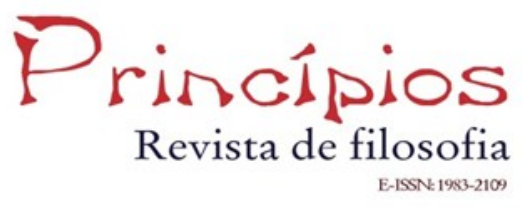


Por Ontologia entendemos o conjunto de todos os princípios do pensamento puro, e não da intuição pura. [...] A Ontologia contempla os princípios de cada coisa,

[e] portanto, estende-se a todas. Tudo que se pode pensar é ou possível ou impossível. [...] O primeiro que é considerado na Metafísica é a palavra objeto, ao qual posteriormente são subordinados todos os outros conceitos. É o conceito universal, supremo na Ontologia. O objeto é possível ou impossível [...]. - A Ontologia vai esclarecer os conceitos elementares. Metafísica Dohna (AA28: 622)

\section{Introdução:}

\section{Sobre as interpretações da filosofia kantiana e da Crítica da razão pura}

Do ponto de vista da história das ideias, a filosofia crítica de Kant tem sido considerada como um divisor de águas na filosofia moderna; quer como prelúdio da filosofia contemporânea, quer como uma instância aquém da qual não se poderia recuar sem incorrer em anacronismo e retrocesso. Não seria exagero dizer que Kant tem sido um dos maiores interlocutores em diversos campos da cena filosófica contemporânea; suas teses e argumentos têm sido discutidos na epistemologia, na ética, na estética, na filosofia política, na filosofia da religião, do direito e da história. Tampouco seria exagerado dizer que sua Crítica da razão pura tem sido uma das obras mais estudadas no último século, e uma das mais controversas; e que essa circunstância permitiria vislumbrar sua relevância e o eventual interesse em estudá-la. Decerto, contudo, por si só não seria o bastante para propor "mais uma" linha de interpretação nem para oferecer uma reconstrução sistemática da Crítica ou de qualquer uma de suas partes; não se existissem outras interpretações concorrentes. Nesse caso, seria preciso primeiro descrever sua situação geral, classificá-las e discuti-las, a fim de 
mostrar que se tem uma alternativa mais adequada ou vantajosa; ou, pelo menos, que se vem preencher uma lacuna.

Uma breve retrospectiva histórica mostraria que após ter dominado a cena alemã e europeia durante a chamada aetas kantiana (c. 1781-1800), a filosofia kantiana deixa temporariamente de atrair a atenção para dar lugar ao auge dos grandes sistemas póskantianos, sobretudo o de Hegel ${ }^{1}$. De fato, após a morte de Hegel seus epígonos dominam a cena filosófica alemã, pelo menos até o renascimento do kantismo na segunda metade do século XIX, sob a famosa consigna: Zurück zu Kant! Daí em diante, porém, a influência e a difusão da filosofia de Kant tornam-se decisivas para a filosofia da ciência, para a filosofia moral e política, para a filosofia da história, e mesmo para a filosofia analítica e a fenomenologia ${ }^{2}$. Primeiro, na Europa, com o advento e a difusão do Neokantismo (i), e das chamadas interpretações metafisicas da filosofia crítica que se lhe opõem (ii), que constituem inicialmente as duas vias principais de interpretação da Escola kantiana alemã; posteriormente, a partir dessas duas vias se originam as ulteriores interpretações histórico-filológicas alemãs e francesas, que acabam por se estender por toda a Europa (iii); e por fim, paralelamente, na Grã Bretanha e nos EUA, através das leituras epistemológicas e analiticamente orientadas que caracterizam a recepção anglo-saxã da obra kantiana no fim do século XIX e ao longo de todo o século XX (iv). Essas são as principais tendências e linhas de interpretação do século $\mathrm{XX}$, as quais se difundem posteriormente na América Latina, e mais recentemente na Ásia e no resto do universo acadêmico hodierno.

Assim, ao longo de todo o século passado, e no pouco tempo que já se vai do atual, a filosofia kantiana é amplamente traduzida, discutida, avaliada e reconstruída por toda parte. Centenas de monografias são escritas em diversas línguas sobre a filosofia transcendental de Kant, e uma boa quantidade delas é dedicada espe-

${ }^{1}$ Sobre isso veja-se Bonaccini (2003).

${ }^{2}$ Sobre isso veja-se, por exemplo, Porta (2011). 
cificamente à primeira Crítica. Mas isso ocorre principalmente no âmbito das línguas alemã e inglesa, e em menor medida na língua francesa. O mesmo, porém, não se pode dizer da situação dos estudos kantianos no Brasil ${ }^{3}$. Embora o Brasil conte com uma das maiores e mais atuantes comunidades de estudiosos da filosofia kantiana na atualidade, poucas são as monografias e estudos publicados devotados à Crítica da razão pura ${ }^{4}$. Com efeito, muito se tem escri-

3 Sobre a história recente dos estudos kantianos no Brasil, veja-se Pérez (2005), Azevedo Marques (2009), Pérez \& Bonaccini (2009; 2012). Aqui, porém, formulo minha posição no que tange às linhas de interpretação reinantes nos estudos kantianos brasileiros em função do interesse pela primeira Crítica e me posiciono de forma ligeiramente diferente de Perez (2005) e Azevedo Marques (2009). No meu entender trabalhos como os de Terra e Rohden pertencem à mesma Escola que eu denomino histórico-filológica, embora Terra combine as tradições francesa e germânica em sua metodologia filosófica e Rohden seja mais especificamente um Kant-Forscher no estilo da tradicional Kantphilologie, sobretudo em seus últimos anos. As interpretações de Almeida e Loparić são claramente epistemológicas, mas combinam metodologias e tradições diversas com filosofia analítica. Assim, o estilo analítico conceitual de Almeida tem raízes na fenomenologia e se aproxima da filosofia analítica de Strawson e Tugendhat, enquanto que a semântica de Loparić se origina em seus estudos de teoria da ciência e evolui em direção à lógica e à filosofia da linguagem. Assim, a menos que consideremos o eventual interesse da linha histórico-filológica por alguns temas "metafísicos" no corpus kantiano como uma linha "metafísica", podemos dizer que prima facie existem basicamente duas linhas mestras na interpretação brasileira sobre Kant, uma historiográfica e uma analítica.

${ }^{4}$ De fato, pelo menos no que diz respeito à Crítica da razão pura, a maioria dos grandes trabalhos brasileiros encontra-se em artigos, ensaios breves e capítulos de livros. Esse é o caso dos trabalhos de Almeida, Landim Filho, Terra, Brum Torres, Hamm, Rohden, Barbosa, Gianotti etc. Se não contarmos as teses e dissertações não publicadas, veremos que são poucos os estudos aprofundados sobre a primeira crítica. Mesmo assim, a maior parte deles se origina de fato em teses e dissertações: Dalbosco (1997), Arrais (2001), Bonaccini (2003), Figueiredo (2005), Pérez (2008), Perin (2008). Note-se, porém, que a maioria desses trabalhos trata de um ou vários aspectos específicos da primeira Crítica, e alguns exploram temas correlatos ao contexto do sistema crítico. A única interpretação global da primeira Crítica que se conhece no Brasil é a de Loparić (2000). O trabalho anterior de Lebrun (1970; 1993), que combina 
to e publicado nos últimos trinta anos sobre a filosofia de Kant no Brasil, sobretudo artigos em revistas e capítulos de livros, mas poucos comentários e tratados sistemáticos devotados a uma re-construção da filosofia transcendental, ou à Crítica da razão pura em particular ${ }^{5}$. Por um lado, as publicações refletem que o interesse maior continua sendo a filosofia prática, sobretudo a filosofia moral e política, e eventualmente sua teoria dos juízos estéticos. Diferentemente dos estudos e monografias em outras línguas, sobretudo a inglesa, na qual abundam os comentários e tratados sistemáticos sobre a Crítica da razão pura, os estudos brasileiros dessa índole são bastante parcos. Oriundos via de regra de teses de doutoramento, e eventualmente de dissertações de mestrado, os trabalhos sobre a obra kantiana no Brasil cobrem geralmente aspectos específicos da filosofia teórica, da filosofia prática, da teoria estética ou do desenvolvimento histórico-conceitual de certas teses e ideias kantianas germinadas após longo período de reflexão ${ }^{6}$. Por outro lado, talvez seja justamente em função dessa circunstância que não existam muitas linhas de interpretação da sua filosofia transcendental como um todo nem da sua Crítica da razão pura como obra capital.

\footnotetext{
o estudo da terceira Crítica com a primeira e com vários outros textos do corpus kantiano, desenvolve uma interpretação histórico-filológica alinhada à tradição das interpretações que se opunham ao neokantismo de Marburgo. Ambas foram e ainda são profundamente influentes nas escolas de Campinas e São Paulo, respectivamente. Vale lembrar, entretanto, que se trata de trabalhos originados a partir de teses escritas na Europa e posteriormente reescritas (Loparić) ou traduzidas (Lebrun) no Brasil.

${ }^{5}$ Um esforço recente contribuiu para amenizar essa lacuna ao reunir trabalhos de vários brasileiros e estrangeiros num comentário da Crítica da razão pura em português (Klein, 2012). Os trabalhos são de alto nível, mas o resultado do empenho é obviamente heterogêneo, já que são muitos autores de países, escolas e orientações diversas, e carece por isso de um fio condutor sistemático.

${ }^{6}$ Cf. a repertório bibliográfico kantiano em português publicado pela Sociedade Kant de Campinas em: < http://www.kant.org.br/bibliografia >.
} 
De modo que à luz da literatura e da situação atual dos estudos kantianos $^{7}$, a princípio podemos dizer que existem basicamente duas linhas mestras na interpretação brasileira da filosofia de Kant, uma historiográfica ou histórico-filológica (de origem franco-germânica) e uma analítica (quer de inspiração anglo-saxã, quer de inspiração continental, quer eventualmente inspirada em ambas as tradições). A primeira utiliza métodos exegéticos da Kantforschung para estudar, analisar e interpretar os textos e as questões geneticamente a partir do contexto histórico e das diversas fontes primárias e secundárias (obras originais, cadernos de apontamentos, fragmentos póstumos de anotações, obras de interlocutores, manuais de sala de aula, comentários clássicos e recentes, etc.). A outra utiliza métodos de análise e justificação lógico-conceitual para abordar as questões e privilegia a análise dos conceitos e das teses em termos de argumentos que podem ser racionalmente discutidos e defendidos ou criticados em termos da filosofia contemporânea, ou pelo menos em termos de uma filosofia de inspiração kantiana contemporaneamente defensável ${ }^{8}$. Obviamente, não se pode negar que muitos autores combinam ambos os estilos. Há poucos trabalhos nos quais a opção por um método implica a exclusão do outro. Todavia, o importante é lembrar que aquilo que permite caracterizar os métodos e classificar as leituras que os aplicam é a ênfase maior ou menor neste ou naquele estilo de interpretação e tratamento.

No que diz respeito à interpretação da Crítica da razão pura, do ponto de vista das pressuposições que me interessa destacar, essas

\footnotetext{
${ }^{7}$ De resto, uma boa ideia da situação geral dos estudos kantianos, em particular no Brasil, pode ser conferida à luz dos títulos brasileiros da Biblioteca do Centro de Investigações Kantianas da UFSC (http://www.cik.ufsc.br/ biblioteca). O mesmo se pode verificar consultado a bibliografia publicada pela Sociedade Kant de Campinas (nenhuma das duas pretende ser exaustiva, mas ambas apresentam um bom panorama da maioria dos títulos publicados). ${ }^{8}$ A escola de Campinas defende a ideia da filosofia kantiana como filosofia contemporânea, ideia com a qual concordo plenamente.
} 
linhas mestras acima descritas se entrecruzam. Basicamente, creio que também existem à primeira vista duas vias de interpretação da primeira Crítica nos estudos brasileiros: uma analítica (i) e outra histórico-filológica (ii). Mas, neste caso, como a analítica bifurca-se em duas, a saber, uma "semântica" (i.i.) e outra "analítico-epistêmica" (i.ii), dá origem ao que se poderia considerar como uma terceira via de interpretação. Assim, a despeito de uma primeira impressão, pelo menos no que diz respeito à Crítica da razão pura, poderíamos dizer que existem no Brasil três vias de interpretação: a analítico-semântica (i.i), a analítico-epistêmica (i.ii) e a históricofilológica (ii) ${ }^{9}$.

A primeira das interpretações analíticas, a semântica (i.i), é devotada a uma interpretação da Crítica, especialmente da Analítica, como uma "semântica transcendental"; a interpretação "analítico-

${ }^{9}$ Poder-se-ia ainda estabelecer uma subdivisão nesta última, em princípio, se fosse levado em consideração o quanto se filia a uma linha de interpretação francófona ou germânica. Mas creio que resultaria num esforço baldio: tanto por causa da semelhança de métodos em ambas as tradições de pesquisa kantiana, quanto pelo fato de que muitos kantianos brasileiros transitam à vontade em ambas as tradições e as combinam. Isso posto, gostaria de instanciar as três vias de interpretação da Crítica da razão pura acima mencionadas: à primeira via pertencem os trabalhos da Escola de Campinas (i.i), sobretudo os de Loparić, Pérez e Faggion; à segunda (i.ii), os trabalhos das Escolas do Rio Grande do Sul (sobretudo os de B. Barbosa, Brum Torres, Guerzoni, Louzado, Altmann, Klaudat), do Rio de Janeiro (sobretudo os de Almeida, Landim Filho, Esteves, Rego, Marques, Levy) e de Santa Catarina (sobretudo os de Franciotti, já que Borges, Volpato, Pinzani, Dall'Agnoll e Barbieri se ocupam com outros aspectos da filosofia kantiana). À terceira (ii) pertencem os trabalhos da Escola de São Paulo (sobretudo Lebrun, Terra e Gianotti, e seus discípulos, Codato, Azevedo Marques, Figueiredo, Licht, Peres), bem como os trabalhos de Valério Rohden, Christian Hamm e alguns de seus alunos, da Escola do Rio Grande do Sul. Não mencionei aqui a chamada Escola kantiana do Paraná porque seus principais membros são oriundos da Escola de São Paulo e comungam com seus métodos. A Escola de Minas, fundada por José Henrique dos Santos, no que diz respeito à interpretação de Kant, e especialmente da Crítica da razão pura, segue sobretudo a terceira via de interpretação (ii) por tradição e por método. 
epistêmica" (i.ii) dedica-se geralmente a uma análise lógica dos objetivos e do método de prova da argumentação kantiana nos principais capítulos e temas da Crítica (Idealismo transcendental, Juízo, Verdade, Dedução, Autoconsciência, Antinomia, Ceticismo, etc.), a fim de reconstruir seus passos e avaliar a consistência e a viabilidade de sua justificação. A terceira linha histórico-filológica (ii), porém, consiste numa análise histórico-genética de aspectos específicos ou de temas centrais da Crítica da razão pura (teoria do juízo, teleologia, sistema, reflexão transcendental etc.). Em que pesem as suas diferenças, todas as três linhas de interpretação convergem quanto ao caráter essencialmente gnosiológico ou epistemológico do projeto filosófico de Kant na primeira Crítica. Tanto as interpretações analíticas como as historiográficas interpretam a Crítica da razão pura respectivamente como uma epistemologia ${ }^{10}$ ou teoria crítica do conhecimento ${ }^{11}$ que se opõe à ontologia e à metafísica da tradição "pré-crítica".

Assim, diferentemente da Alemanha, onde surgiram pela primeira vez as chamadas interpretações "metafísicas" da Crítica da razão pura $^{12}$, e dos EUA, da Grã-Bretanha e os outros países de língua inglesa, onde sempre predominaram interpretações epistemo-

\footnotetext{
${ }^{10}$ Uso o termo "epistemologia" e termos derivados (epistemologia, epistêmico, etc) num sentido que compreende questões de conhecimento e de justificação e engloba tanto o que outrora chamava de gnosiologia ou teoria do conhecimento como questões de epistemologia contemporânea (teoria da proposição, do significado, de verdade etc). Por isso digo que questões semânticas são epistemológicas, embora de início faça uma distinção com o intuito de caracterizar os diferentes estilos de análise em jogo, como por exemplo, a diferença entre a semântica de Loparić (2000) e análise de Almeida (2012).

${ }^{11}$ Uso este termo para caracterizar o modo como a filosofia crítica de Kant ou a teoria do conhecimento contida na Crítica da razão pura são interpretadas pela interpretação histórico-filológica.

${ }^{12}$ Sobretudo Wundt (1924), Heidegger (1929), Martin (1951). Cf. Paulsen, 1899. Mais recentemente apareceram outras interpretações metafísicas ou ontológicas de Kant na Alemanha (p. ex.: Ficara (2006), Hahmann (2009)) e na França (sobretudo, Freuler (1992) e Chenet (1994)). Voltaremos sobre esse ponto.
} 
lógicas e analíticas ${ }^{13}$, mas assistiram recentemente a construção de interpretações "metafísicas"14, não existe no Brasil uma linha de interpretação propriamente "metafísica" nem "ontológica"15. É verdade que alguns estudos que seguem uma linha historiográfica ou reconstrutiva têm salientado aspectos ou compromissos metafísicos presentes no projeto kantiano ${ }^{16}$; mas nenhum se apresenta como uma interpretação eminentemente "metafísica", e muito menos "ontológica"17. Por isso, pode-se afirmar a princípio que as poucas interpretações sistemáticas da Crítica da razão pura no Brasil, tanto as historiográficas como as analíticas, são em alguma medida epis-

\begin{abstract}
${ }^{13}$ Penso, sobretudo, em Prichard (1909), Paton (1936), Wolff (1963), Strawson (1966), Bennet (1966), Melnick (1973), Beck (1978), Walker (1978), Aquila (1983), Allison (1983; 2004), Guyer (1987; 2006), Kitcher (1990), Van Cleve (1999), Dicker (2004), Bird (2006), Abela (2003) etc.

${ }^{14}$ A rigor, o que se chama de interpretação metafísica nos EUA, pelo menos no caso de Ameriks (1982; 1992; 2000; 2005) e Watkins (2005), é uma interpretação histórico-genética que combina os métodos alemães da Kantforschung com o estilo de exposição e argumentação analítico-conceitual característico da escola americana. O epíteto dessas leituras ("metafísica") costuma ser justificado por uma leitura de Kant que acentua seus vínculos com a tradição racionalista alemã em oposição às leituras epistemológicas tradicionais, que acentuam a relação Kant-Hume.

${ }^{15}$ Com raras exceções: Dalbosco menciona a possibilidade de interpretar a filosofia crítica como uma ontologia e insinua certa "numenologia" kantiana (2000, p. 22-23), mas se trata de um caso isolado. A dissertação do meu amigo e colega L. Yanzer Portela (2001) (que por mero acaso coorientei, ainda que sua inspiração central tenha sido provocada pelo estilo de B. Barbosa e um ensaio de Cabrera (1985)), é de fato uma exceção e uma defesa sistemática da Crítica da razão pura como sendo essencialmente uma metafísica. Mas vale lembrar que minha tese já defendia, contra a corrente, uma interpretação metafísica do idealismo transcendental de Kant (Bonaccini, 1997). Contudo, a interpretação ontológica que pretendo defender aqui vai numa outra direção.

${ }^{16}$ Por exemplo: Lebrun (1993), Terra (2003), Figueiredo (2005), Licht dos Santos (1997).

${ }_{17}$ Meu colega Paulo Licht dos Santos está trabalhando numa interpretação "ontológica", contra Allison e Longuenesse, segundo me confessou no VII Congresso Interamericano de Filosofia. Mas ainda não tive acesso a seu trabalho, que me interessa por razões óbvias.
\end{abstract}


temológicas: todas interpretam seu escopo central quer em termos de uma teoria (crítica) do conhecimento, quer em termos de uma epistemologia analiticamente exequível, quer em termos de uma epistemologia semântica.

Neste contexto, meu objetivo central é reivindicar uma interpretação da Crítica da razão pura como uma nova ontologia ${ }^{18}$. Por "ontologia" aqui entendo uma teoria a priori dos objetos, não uma ontologia no sentido metafísico nem no sentido existencial de uma "ontologia fundamental"19. A saber, entendo por ontologia uma "teoria dos objetos" enquanto teoria categorial que opera uma reconstrução meta-teórica da estrutura formal e objetiva de nosso mundo a partir da estrutura objetal do nosso pensamento e das nossas faculdades cognitivas ${ }^{20}$. Mas isso certamente não significa que a teoria não apresente consequências epistemológicas e semânticas importantes ${ }^{21}$. A teoria de Kant é um bom exemplo da conexão entre questões ontológicas, epistêmicas e semânticas. O ponto a destacar é que na interpretação que pretendo desenvolver a ontologia não é subordinada à epistemologia. Esta última é que pressupõe a primeira: a teoria acerca das condições de possibilidade do conhecimento dos objetos pressupõe uma teoria acerca dos obje$\operatorname{tos}^{22}$.

No que se segue apresento uma abordagem preliminar de minha proposta que deixa transparecer a linha básica da minha interpretação analítica e sistemática da Crítica da razão pura e creio que permite justificar minha concepção da Analítica Transcenden-

\footnotetext{
${ }^{18}$ Apresentei o marco geral dessa via de interpretação e reconstrução da Crítica da razão pura em: Bonaccini (2013b; 2014). Em Bonaccini (2012) ofereci uma reconstrução preliminar da Estética Transcendental.

${ }^{19}$ Cf. Heidegger (1927; 1929).

${ }^{20}$ Embora Heidegger pareça por momentos se aproximar de afirmações como essa (1929; 1984 [1935-6]), sua leitura segue uma tese que se origina em Fichte (sobre o papel central da imaginação) e toma um rumo que considero metafísico num sentido diverso do que pretendo desenvolver.

${ }^{21}$ Isto é, questões de justificação e de significação.

${ }^{22}$ Apresentei um esboço sumário desses momentos em Bonaccini (2013a).
} 
tal como ontologia ${ }^{23}$. Note-se que neste momento não vou discutir interpretações histórico-filológicas, mas somente as "epistemológicas" e "semânticas". Isso obedece a duas razões: primeiro, porque muitas interpretações histórico-filológicas são simpáticas a uma interpretação ontológica (embora geralmente num sentido diverso do acima proposto ${ }^{24}$ ), e eventualmente compatíveis com uma interpretação dessa natureza; segundo, porque tendem a enfatizar a crítica do conhecimento em oposição à ontologia clássica e racionalista, comprometendo-se também com a ideia de que o termo "transcendental" tem a ver com "conhecimento", não com constituição de objetos; ou, então, entendem essa "constituição" como as leituras epistemológicas, a saber, em termos lógico-epistêmicos, mas não, como penso que deveria ser, em termos lógico-ontológicos). Assim, meu problema não é com os métodos de exegese e de interpretação genética, mas com a pressuposição que as interpretações histórico-filológicas têm em comum com as outras interpretações que aqui discuto: que a empresa de Kant tem a ver essencialmente com as condições de possibilidade do conhecimento objetivo e que o aspecto transcendental da "constituição de objetos" diz respeito apenas e principalmente às condições de possibilidade do conhecimento. Desse modo, para expor e justificar a minha ideia central, basta tratar do princípio comum às interpretações epistemológicas e semânticas.

\section{A Filosofia Transcendental \\ e a teoria dos objetos a priori}

Minha estratégia metodológica aqui consiste em descrever o quadro geral de minha interpretação em quatro breves seções. Na

\footnotetext{
${ }^{23}$ Trata-se de um excerto em português de resultados posições defendidas em outra ocasião e submetidos para publicação em inglês e espanhol. Os resultados apresentados a seguir pressupõem por sua vez outros resultados anteriores já publicados no que diz respeito à interpretação da Estética Transcendental (Bonaccini, 2012; 2013a).

${ }^{24}$ Por exemplo, Chenet (1994) e Terra (2003).
} 
primeira (2.1), explico em termos gerais como considero as interpretações epistemológicas e semânticas e sugiro que questões de epistemologia e semântica são dependentes da teoria kantiana dos objetos. Para sustentar a minha ideia (de que Analítica pode ser lida como uma nova ontologia) discuto brevemente alguns trechos da Crítica e de outros textos kantianos publicados e póstumos que permitem sustentar uma interpretação ontológica da Filosofia Transcendental, notadamente da Analítica, e são compatíveis com a minha leitura (2.2). A seguir (2.3), tento circunscrever melhor a minha ideia mediante uma reconstrução parcial da estrutura metódica da Analítica dos Conceitos. Por fim (2.4), aplico os resultados obtidos a uma breve consideração do estatuto das Analogias da experiência. Mas vale ressaltar que a última seção apresenta uma linha de argumentação plausível e programática que ainda requer mais trabalho de análise e justificação.

\subsection{Ontologia, epistemologia e semântica}

Nesse sentido, não pretendo interpretar a Analítica transcendental de tal modo que as categorias sejam reduzidas a meras funções lógicas nos juízos (Walker, 1978), nem tampouco a simples condições epistêmicas (Allison, 1983) ou semânticas (Loparić, 2000; Pérez, 2008). Na sequência de uma pista deixada por Kant na terceira Crítica, vou considerá-las como predicados ontológicos ${ }^{25}$ : formas que constituem objetos ao fornecerem a priori a estrutura da "objetualidade" aos elementos que compõem o inventario do mundo, tornando-os, precisamente, "objetos" do mundo em geral, sendo os objetos do mundo empírico uma classe particular de objetos cujo conhecimento é possível e efetivo. Isso porque todo e qualquer objeto é, sobretudo, uma estrutura formal construída ("minddependent") e adquirida a priori por nossas faculdades cognitivas a

\footnotetext{
${ }^{25}$ Kant faz uso da expressão "ontologische Prädicate" na introdução à terceira Crítica (Cf. KU, Einleitung V, AA 5: 181).
} 
partir da simples ocasião de um input sensorial dado ${ }^{26}$; uma estrutura que designa o modo como tudo que pode ser pensado e conhecido pode de fato ser pensado e conhecido como "objeto". Coisas em geral, entes de pensamento ou do mundo, somente são acessíveis a seres como nós na medida em que são concebidos e pensados por categorias como "objetos". Desse modo, categorias enquanto predicados ontológicos e conceitos de objeto em geral são então meta-objetos: porque não só nenhum conceito de objeto empírico pode deixar de pressupô-las como meta-conceitos, mas porque os próprios objetos empíricos não seriam "objetos" se não fosse por elas; e tampouco nenhum "ente" fictício ou real, atual ou possível, poderia se tornar "objeto" de consideração sem elas. Afinal, são elas que dão a forma de "objetos" às coisas.

Uma consequência dessa interpretação é que do ponto de vista formal as categorias seriam "objetos a priori", e os princípios do entendimento puro que as contêm não seriam meramente epistemológicos ou semânticos, a saber, condições a priori da possibilidade do conhecimento verdadeiro ou da significação de nossos juízos, mas também princípios ontológicos. Pois no contexto da Analítica dos princípios os conceitos puros do entendimento expressam categorias esquematizadas que representam a estrutura formal de todos os "objetos" que podem ser objetos da experiência possível, i. é, "as condições necessárias da unidade sintética do múltiplo da intuição em uma experiência possível" (A158/B197). Assim, tanto a "epistemologia" identificada pela maioria dos intérpretes no estabelecimento e na justificação das condições de possibilidade do conhecimento e da verdade na Analítica transcendental ${ }^{27}$, quanto a chamada "semântica a priori" ou "semântica

\footnotetext{
${ }^{26}$ Sobre a aquisição originaria o a priori das formas da intuição e das categorias a partir de nossa a faculdade de conhecimento veja-se, por exemplo, a Refl. n. 4851 (AA 18: 8-9) (apud Azevedo Marques, 2007, p. 457). Cf. Oberhausen 1997, p. 6 et seq. Cf. também Azevedo Marques (2008).

${ }^{27}$ Aqui me refiro a trabalhos sobre Kant que já são clássicos em língua inglesa, como os de H. J. Paton (1936), R. P. Wolff (1963), P. F. Strawson (1966), R.
} 
transcendental" de todos os juízos sobre objetos que podemos conhecer a partir das categorias e dos princípios do entendimento puro $^{28}$ pareceriam ser antes uma consequência do modo como nossa mente e nossas capacidades cognitivas estruturam a priori o mundo como um "mundo de objetos" ${ }^{29}$. Numa palavra: ainda que

Melnick (1973), e ainda os mais recentes de Henry E. Allison (1983; 1996; 2004), P. Guyer (1987), J. Van Cleve (1999) etc. Todos deixam de lado, criticam ou menosprezam o aspecto metafísico da Crítica da razão pura e destacam a contribuição kantiana para a epistemologia.

${ }^{28}$ Loparić (2000) defende que a teoria kantiana da possibilidade dos juízos sintéticos a priori constitui o conteúdo essencial de sua Crítica da razão pura e por isso a mesma pode ser interpretada como uma semântica transcendental, já que define as condições a priori da significação da verdade e da falsidade dos juízos sobre objetos e permite resolver os problemas que são necessariamente postos pela razão pura. Veja-se Pérez (2003; 2008). Cf. G. Schönrich (1981, p. 13 et seq./117 et seq.) e W. Hogrebe (1974).

${ }^{29}$ A propósito, outro trabalho recente que segue uma linha de interpretação epistemológica é Kant's theory of knowledge, de George Dicker (2004). Em sua análise do que ele chama "o argumento central" da primeira Crítica, cita uma passagem importante do §14 (A94/B126), no qual Kant menciona especificamente o princípio da Dedução, de acordo com o qual as categorias devem ser justificadas como condições a priori da possibilidade da experiência (Dicker, 2004, p. 86). Porém, a maneira como Dicker interpreta a passagem sugere uma visão parcial: a expressão "condições a priori da possibilidade da experiência" indica na realidade as condições "dos objetos da experiência possível", ou "da possibilidade dos objetos da experiência" (A158/B197), não somente do "conhecimento empírico" de objetos espaciotemporais ou da "consciência" de nossos estados subjetivos, como Dicker pareceria sugerir (cf. 2004, p. 8889). Com efeito, é preciso notar que embora o conceito de "experiência" seja por vezes definido como "conhecimento empírico" o trabalho de Kant não se resume a una análise das condições do conhecimento "empírico", já que sua preocupação maior é com o conhecimento a priori (Greenberg, 2001, p. VIII), sintético a priori, que vem a ser a estrutura de todo pensamento e conhecimento; e somente por isso é também conhecimento da experiência. A tese que vou desenvolver é que as categorias são condição sob as quais pensamentos e as percepções de coisas tornam-se percepções de "objetos" atuais ou possíveis, e por isso são condições dos objetos enquanto tais antes de serem condições do conhecimento dos objetos (veja-se A93/B126 e cf. KU, Einleitung, V, AA 5: 181). 
a epistemologia e a semântica de algum modo estejam presentes na teoria kantiana, pressupõem uma ontologia formal, ou seja, uma meta-teoria dos objetos como entidades que somente podemos pensar (objetos ${ }^{1}$ ), entidades que não somente podemos pensar, mas também conhecer (objetos ${ }^{2}$ ), e ainda entidades que podemos pensar como objetos mas não conhecer, como é o caso dos objetos na ideia $\left(\text { objetos }^{3}\right)^{30}$.

Meu ponto de partida é uma compreensão das categorias e das Analogias da experiência que se inspira nas chamadas leituras metafísicas de Kant ${ }^{31}$ (ainda que nenhuma delas proponha uma ontologia como teoria formal dos objetos). A Lógica Transcendental da primeira Crítica, sobretudo a Analítica, costumam ser entendidas há bastante tempo como se fossem apenas parte de um mesmo enfoque epistemológico de Kant, em franco distanciamento crítico

\footnotetext{
${ }^{30}$ Em outros trabalhos (Bonaccini, 2003, p. 169; 2013, p. 212 et seq.) estabeleci uma distinção entre "conhecimento de objetos a priori (inteligíveis)" e "conhecimento a priori de objetos (sensíveis)" para explicar como Kant interpreta a confusão básica da metafísica (que conduz à pretensão ao conhecimento de coisas em si mesmas) e como a resolve. Essa distinção, do ponto de vista dos objetos implicados, corresponde a princípio à distinção acima esboçada entre $\left(\right.$ objetos $\left.^{1}\right)$ e $\left(\right.$ objetos $\left.^{2}\right)$ : categorias $\left(\operatorname{conceitos}\right.$ puros $=\left(\right.$ objetos $\left.^{1}\right)$ ) podem ser confundidos com a concepção de (objetos ${ }^{3}$ ) ou bem entendidos e conhecidos como (objetos ${ }^{2}$ ). Com efeito, Kant ensina na Crítica que como as categorias se referem a priori a objetos mediante predicados do pensamento puro, não da intuição e da sensibilidade, não se restringem aos objetos da sensibilidade (obje$\left.\operatorname{tos}^{2}\right)$ (B120). Assim, permitem pensar qualquer objeto $\left(=\right.$ objetos $\left.^{1}\right)-$ nesse sentido é que são conceitos puros de um objeto em geral (Begriffe von einem Gegenstande überhaupt) - e podem ser confundidas com o conhecimento de objetos inteligíveis (objetos de uma intuição intelectual $=$ objetos $^{3}$ ). Daí porque é preciso demonstrar que seu âmbito de aplicação e uso legítimo são os objetos da experiência possível (objetos²).

${ }^{31}$ Refiro-me àquelas leituras que surgiram no século passado a partir do célebre livro de Wundt, Kant als Metaphysiker (1924), e se opuseram ao Neokantismo de Marburgo, como Heidegger (1929), Heimsoeth (1956) e Martin (1951). Sobre a tradição de interpretação metafísica de Kant, veja-se o excelente estudo de Elena Ficara (2006, p. 11 et seq.).
} 
face à metafísica em general e à ontologia em particular ${ }^{32}$. A origem dessa posição remonta ao neokantismo de Marburgo, mas se origina, sobretudo, no influente estudo de Strawson (1966).

Strawson rejeita o idealismo transcendental como um resquício metafísico e tenta salvar o que considera vivo e revolucionário na teoria kantiana, seu "argumento" analítico e seu "princípio de significado" (Strawson, 1966, p. 16 et seq./22 et seq./38 et seq./42 et seq./235 et seq.), operando de certo modo uma semantização do critério epistêmico obtido na Analítica, uma vez que os limites da experiência transformam-se nos limites que demarcam os domínios das proposições significativas e das que não o são. Nesse contexto, Strawson rejeita de modo claro e veemente a Dedução Metafísica (1966, p. 88/117) e a ideia de categorias como conceitos puros do entendimento, reinterpretando Kant dentro de uma perspectiva mais empirista e recuperando o argumento da Dedução transcendental do ponto de vista de uma estratégia epistêmica de refutação anticéptica (1966, p. 78 et seq./82 et seq./118 et seq.). Por sua vez, as Analogias da experiência são entendidas como uma parte essencial do argumento analítico de Kant para resolver os problemas epistemológicos colocados por Hume (1966, p. 118 et seq. $)^{33}$.

\footnotetext{
${ }^{32}$ Após o esmaecimento do Neokantismo, do Positivismo Lógico de Viena e das leituras metafísicas na Alemanha são justamente as leituras britânicas (Paton, 1936; Strawson, 1959; 1966; Bennet, 1966) que reabilitam o interesse por Kant no século passado, em meio à briga entre as escolas de Oxford e Cambridge e ao revival de Hegel em Paris. São essas leituras enfatizam a epistemologia da primeira Crítica, mas não mais entendida como uma teoria do conhecimento científico (como em Marburgo) ou da linguagem da ciência (como no Círculo de Viena). A leitura de Paton foi muito influente por um tempo, e mesmo a de Bennet, mas a de Strawson é certamente a mais influente de todas, tanto que a maioria das leituras de língua inglesa lhe deve alguma coisa.

${ }^{33} \mathrm{O}$ que é parcialmente verdadeiro, já que o esquema strawsoniano se aplica bem à segunda analogia, e eventualmente à primeira, mas não tão bem à terceira, da qual a maioria dos intérpretes não se ocuparam até pouco tempo atrás por considerá-la redundante (Allison, 2004, p. 268 et seq.). Para uma interpretação diferente de Strawson e a linha de intérpretes que o acom-
} 
Além disso, as Analogias são entendidas como tão somente aquelas condições de possibilidade do conhecimento que nos permitem distinguir a sucessão de nossas percepções ou estados subjetivos da sucessão objetiva dos fenômenos que percebemos interagindo no espaço e no tempo e obedecendo a leis causais (1966, p. 122 et seq. $)^{34}$.

Entrementes, embora o livro de Strawson e sua interpretação tenham sido muito criticados nos últimos anos, sobretudo depois de que o debate sobre os chamados "argumentos transcendentais" perdeu fôlego e interesse ${ }^{35}$, e o livro de Allison mostrou os limites de sua interpretação do Idealismo Transcendental ${ }^{36}$, o fato é que quase todos os autores de língua inglesa (e muitos outros de outras tradições) foram e continuam sendo influenciados por sua leitura. Tanto é assim que na maioria dos casos se interpreta as categorias e as Analogias como princípios essencialmente epistemológicos ${ }^{37}$. Outras vezes são entendidas como princípios lógicos, a saber, de uma lógica transcendental, o que é correto; mas via de regra a leitura vem acompanhada de uma interpretação apenas epistêmica da lógica transcendental.

Assim, hoje tudo se apresenta como se Kant fosse essencialmente um crítico do conhecimento ou um precursor da filosofia

panham (Melnick, Walker, Guyer, Kitcher, Van Cleve etc), veja-se Watkins (2005).

${ }^{34}$ Neste aspecto tem sido seguido pela maioria dos intérpretes, sobretudo no âmbito dos estudos kantianos de língua inglesa.

${ }^{35}$ Sobre o debate e torno dos argumentos transcendentais há inúmeros trabalhos e é difícil fazer uma lista. Veja-se, por exemplo, Strawson (1966) e Stroud (1968). Cf. Körner (1974), Brueckner (1983; 1984), Genova (1984), Cassam (1987), Stern (2000). No Brasil, Almeida, Barbosa, Esteves, Franciotti, Rohden e Loparić são alguns dos que se ocuparam disso, mas não tive acesso a todas as publicações ainda.

${ }^{36}$ Allison, 1983.

${ }^{37}$ Isso é o que sugerem os trabalhos de Melnick (1973), Guyer (1987), Allison (1983; 2004) e mesmo Longuenesse (2005). Eric Watkins é uma exceção: considera que categorias e princípios são também ontológicos (2005, p. 186 et seq.); e também um estudo mais recente de Chiba (2012, p. 8). 
analítica, em ambos os casos um epistemólogo por excelência, e mesmo antimetafísico ${ }^{38}$. Outras vezes é apresentado como um metafísico sem remédio que deve ser mandado ao museu da história das ideias para dar passo a autores ou teorias mais atualizadas com as questões contemporâneas ${ }^{39}$.

Nesse contexto, não nego o alcance epistêmico do projeto kantiano, nem sua crítica da ontologia tradicional de origem wolfiana. Defendo apenas que ao enfatizar esse aspecto epistêmico da sua crítica da razão perde-se o seu importe metafísico e a radicalidade do chamaria sua nova ontologia ${ }^{40}$. Nesse sentido, penso que não se

${ }^{38}$ É verdade que houve algumas exceções em língua inglesa, como é o caso de Ameriks (1982; 1992; 2000; 2003) e Watkins (2005), mas é mais comum em alguns estudos alemães (Wohlers, 2000; Chiba, 2012; Ficara, 2006). Também há exceções na escola de Buenos Aires, que tem seguido uma línea que remonta à tradição alemã de interpretação metafísica, sobretudo nos trabalhos de Thisted (2008) e Caimi (1989; 1991; 1992). Ainda assim, são exceções. Como acima mencionado, no Brasil predominam combinações de exegese e análise nas escolas do Rio de Janeiro, Campinas e Rio Grande do Sul, com uma ênfase mais epistemológica (Rio e Porto Alegre) ou semântica (Campinas). Os trabalhos de Loparić (2000) e Almeida (2012) são uma boa amostra disso. A escola de São Paulo segue uma linha exegética que combina os métodos da tradição alemã com a historiografia francesa (Cf. Rauscher, 2012, p. 6-7).

${ }^{39}$ Essa pareceria ser a leitura de alguns entusiastas do positivismo lógico, ou pelo menos de gente que também vê sérios problemas na noção de "juízos sintéticos a priori”. Sobre isso veja-se, por exemplo, Coffa (1991, p. 1 et seq./ 8 et seq.); Westphal (2010, p. 402). Cf. Loux; Zimmermann (2003, Introduction, p. 1-7). Cf. Loparić (2000) e Hanna (2001). Nietzschianos e hegelianos por vezes partilham dessa visão com alguns filósofos da linguagem.

40 Alguns autores de mencionaram recentemente que existe algum tipo de ontologia em Kant: B. Longuenesse fala de uma "ontology of appearances" (2005, p. 32); e outrora falara de uma "ontology as immanent thinking" (1998, 394 et seq.). No Brasil, a dissertação acima mencionada de L. Y. Portela defende uma "ontologia do ser sensível" (2001, Conclusão). K. Chiba sugere que o Idealismo Transcendental deve ser entendido como algo semelhante, a saber, una "ontologia espaciotemporal" de corte antirrealista (2012, p. 1-2). R. Greenberg menciona que "a epistemologia de Kant" envolve uma "ontologia de objetos", mas desvincula a última da primeira: "It is only a theory of the possibility of a priori knowledge, not a theory of the possibility of empirical 
trata simplesmente de opor as categorias kantianas como "predicados do conhecer" às categorias entendidas no sentido tradicional de "predicados do ser" (Loux, 2002, p. 6 et seq.), a fim de distinguir as duas abordagens atualmente reinantes em termos de ontologia categorial; e como Kant pareceria sugerir prima facie ao contrastar sua Lógica transcendental com a lógica formal clássica tomada como uma sintaxe negativa, que somente ofereceria um critério negativo de verdade (A81/B107). Tampouco acredito que os Princípios do entendimento puro, particularmente as Analogias,

knowledge, that is committed to an ontology of objects that is distinct from the conditions of the possibility of the knowledge in question, that is, the knowledge whose possibility the theory is supposed to explain. Accordingly, [...] Kant's transcendental ontology - the ontology of his theory of the possibility of specifically a priori knowledge - must be distinct from the conditions of that possibility, a thesis undergirded by my interpretation of that ontology. This thesis in particular has important consequences for a new interpretation of Kant's transcendental idealism as well. Like the first, this thesis, too, is at odds with standard Anglophone commentary on the Critique." (2001, Preface, p. VIII). Também C. Wohlers (2000) menciona a ontologia da gnosiologia de Kant (p. 12). Em contrapartida, Elena Ficara (2006) investiga acertadamente a possibilidade de uma nova ontologia em Kant e os problemas implicados pela aparentemente conflitiva relação entre os conceitos de ontologia, lógica e filosofia transcendental (p. 11 et seq./107 et seq.), chegando a explicar a justaposição dos três de maneira bem documentada e consistente, salientando a importância do método e da lógica transcendental para a ontologia de Kant (p. 191 et seq.). Mas não chega a entender o caráter metateórico e constitutivo dos "objetos" na Analítica (Cf. p. 121 et seq./168 et seq.). Tampouco Chiba, que faz uso do termo "ontologia" de modo próximo ao nosso (2012, p. 7-10), mas sugere que não é o de Kant, enquanto que eu acredito que este uso quase contemporâneo do termo é o que melhor capta o novo sentido revolucionário da ontologia crítica e formal kantiana. Com efeito, minha ideia central é que sem uma ontologia formal como a teoria dos objetos que Kant oferece nada pode ser considerando sequer como "objeto", muito menos como existente ou possível (pensável). Kant sugere isso, a meu ver, ao dizer que categorias as são as condições sob as quais "coisas" podem tornar-se objetos: a categoria é a condição, a "Bedingung a priori [...] unter der allein Dinge Objecte unserer Erkenntniß überhaupt werden können" (AA 5: 181; grifo nosso). 
sejam meramente princípios epistemológicos; quer como meras condições da objetividade dos juízos empíricos (Strawson \& Cia), quer como princípios que completariam a tarefa crítica de uma semântica a priori da verdade dos nossos juízos cognitivos acerca da natureza (Loparić, 2000).

Penso que Kant apresenta uma teoria "construtivista" dos objetos muito mais complexa, no sentido de que a diversidade das "coisas" ou entidades é constituída como um conjunto de objetos por estruturas cognitivas operativas para se tornarem acessíveis. De modo que mesmo quando não parecem depender de nossas faculdades, por terem uma existência independente, continuam dependendo formalmente delas; continua sendo necessário que entidades realmente existentes sejam dadas e consideradas como extramentais a partir de seu "input" ${ }^{41}$ sensorial. Mas isso não significa que este material dado não tenha de ter sido já sempre ordenado, estruturado e compreendido de acordo com certos princípios para chegar a ser propriamente processado e interpretado, identificado e reconhecido como um objeto, ao qual, por ser "objeto", poderemos então predicar qualidades espácio-temporais, propriedades e relações causais enquanto condições de sua representação ou de seu conhecimento ${ }^{42}$.

Do ponto de vista estritamente metateórico estabelecido pela reflexão transcendental, para o conhecimento dos "objetos", bem antes que as condições epistemológicas da verdade e da falsidade

\footnotetext{
${ }^{41}$ A metáfora do modelo de processamento informacional vem de Falkenstein (1995, 8 et seq.), embora não concorde com seu "intuicionismo", sobretudo sua leitura de uma ordem intuitiva do material sensorial, prévia e independente da atividade do entendimento.

42 Allison entende que espaço, tempo e categorias são condições epistémicas enquanto condições da representação dos objetos da experiência possível (1983; 1996, p .4; 2004, p. 11). Almeida, inspirado em Strawson, entende que o objetivo fundamental de Kant é demonstrar a possibilidade do conhecimento objetivo, e interpreta a Dedução transcendental como uma prova de necessária conformidade de nossas intuições às categorias enquanto condições necessárias do conhecimento dos objetos (2012, p. 27 et seq.).
} 
de nossos juízos sejam ou não satisfeitas em função do significado e da referência de seus conceitos a objetos atuais, possíveis ou impossíveis, é preciso que outras condições já sempre tenham sido satisfeitas. Do ponto de vista da nossa experiência do mundo, em abstração das condições de sua existência atual, que somente pode ser dada ou constatada empiricamente, deve haver condições ontológicas $^{43}$, a saber, regras operando como condições a priori unicamente sob as quais os elementos do nosso mundo que se apresentam como independentes de nós (as coisas ou entes em geral) podem ser pensados e conhecidos como "objetos". Somente então, uma vez satisfeitas, é que nossos juízos podem ser a priori referidos a "objetos", e somente na medida em que podem ser referidos a objetos" é que são passíveis de verdade ou falsidade.

Minha ideia básica, por tanto, não é negar que a Lógica transcendental inclua uma epistemologia, e ainda uma semântica $a$ priori. Mesmo aceitando-as de bom grado, a minha questão é que devem pressupor uma ontologia formal entendida como uma teoria transcendental dos objetos que podemos pensar (ontologia ${ }^{1}$ de objetos ${ }^{1}$ ) e conhecer (ontologia ${ }^{2}$ de objetos ${ }^{2}$ ), e mesmo de objetos que necessariamente devemos pensar, mas não podemos conhecer, como as ideias de Deus, da alma e da liberdade (ontologia ${ }^{3}$ de objetos ${ }^{3}$ ). Essa é para mim a maneira como Kant entendia sua filosofia transcendental: "transcendental" significa ontológico no sentido de ser a priori constitutivo da objetualidade dos objetos qua "objetos". Mas com a grande diferença (em relação ao sentido tradicional) que os elementos ditos "transcendentais" são neste caso

\footnotetext{
${ }^{43}$ Allison $(1983 ; 1996 ; 2004)$ nega "condições ontológicas" porque entende o uso do termo ontológico em um sentido limitado à ontologia clássica e précrítica. Portela (2001) percebe que aquilo que Allison chama de condições epistêmicas deve ser considerado como ontológico, mas desconsidera o fato de que as condições sensíveis podem ser chamadas ontológicas em um sentido diferente (como em Chiba (2012), por exemplo), já que não são condições dos $\left(\right.$ objetos $\left.^{1}\right)$, mas apenas de (objetos ${ }^{2}$ ).
} 
mind-dependent ${ }^{44}$. E penso que certos textos de Kant dão apoio a minha interpretação.

\subsection{Analítica e ontologia}

Assim, mesmo Loparić, por exemplo, reconhece na primeira Crítica que a Filosofia transcendental é identificada por Kant à ontologia, ao citar uma famosa passagem da Arquitetônica ${ }^{45}$. Como é sabido, na Arquitetônica encontramos uma das duas passagens da primeira Crítica nas quais aparece o termo wolfiano Ontologie ${ }^{46}$. Nesse momento, Kant descreve a "filosofia transcendental" como "ontologia" na medida em que considera "o entendimento e a própria razão num sistema de todos os conceitos e princípios que se referem a priori a objetos em general, sem assumir que [quaisquer] objetos seriam dados" (KrV, A845/B873). O que pode perfeitamente ser entendido como uma maneira de dizer que a teoria categorial da Analítica ocupa o posto da Philosophia prima de Wolff, só que agora dentro do novo marco crítico ${ }^{47}$. Além do mais, é nesse sentido que se deve entender a assertiva de Kant na outra passagem (A247/B303), segundo a qual se deveria abandonar o orgulhoso nome de "Ontologia". Tal como geralmente é lida, parece como se Kant rejeitasse a possibilidade de toda e qualquer ontologia. Mas não parece que esse seja o caso, já que se refere aos wolfianos.

Também na Introdução à terceira Crítica Kant faz um uso análogo do termo, só que dessa vez mais específico e crucial. Ao propor o princípio de finalidade formal da natureza enquanto princípio transcendental da faculdade de julgar, Kant contrasta-o com as

\footnotetext{
${ }^{44}$ Noutro lugar me referi a essa distinção entre objetos ${ }^{2}$ e objetos ${ }^{3}$, a partir da possibilidade de uma ontologia ${ }^{1}$ de objetos ${ }^{1}$ da seguinte maneira: "Kant não entende conhecimento racional (i. é, "puro"), como um conhecimento de objetos puros, mas antes como um conhecimento puro de objetos" (Bonaccini, 2013b).

45 2000, p. 11.

${ }^{46}$ A outra passagem é KrV A247/B303.

${ }^{47}$ Elena Ficara (2006) interpreta essa passagem de modo análogo.
} 
categorias enquanto princípios transcendentais. Mais especificamente, adota como exemplo a categoria esquematizada da substância enquanto princípio a priori do conhecimento dos objetos e acrescenta que esse princípio exige "predicados ontológicos" (categorias não esquematizadas) que devem ser pensados para poder conhecer aqueles objetos de modo a priori:

Um princípio transcendental é aquele por um meio do qual se representa a priori a condição universal unicamente sob a qual as coisas podem se tornar objetos de nosso conhecimento em geral [...]. Assim, o princípio do conhecimento de corpos como substâncias, e como substâncias variáveis, é transcendental quando se diz que sua mudança deve ter uma causa, mas é metafísico quando se diz que sua mudança deve ter uma causa externa: porque, no primeiro caso, o corpo apenas pode ser pensado através de predicados ontológicos (conceitos puros do entendimento), por exemplo, como uma substância, para conhecer a proposição $a$ priori, mas no segundo o conceito empírico de um corpo (tal como um objeto em movimento no espaço) deve ser colocado na base desta proposição $\left[\ldots . .{ }^{48}\right.$

Ora, como entender o uso da expressão "predicados ontológicos" para caracterizar os conceitos puros do entendimento, a não ser

\footnotetext{
48 "Ein transscendentales Princip ist dasjenige, durch welches die allgemeine Bedingung a priori vorgestellt wird, unter der allein Dinge Objecte unserer Erkenntniß überhaupt werden können. Dagegen heißt ein Princip metaphysisch, wenn es die Bedingung a priori vorstellt, unter der allein Objecte, deren Begriff empirisch gegeben sein muß, a priori weiter bestimmt werden können. So ist das Princip der Erkenntniß der Körper als Substanzen und als veränderlicher Substanzen transscendental, wenn dadurch gesagt wird, daß ihre Veränderung eine Ursache haben müsse; es ist aber metaphysisch, wenn dadurch gesagt wird, ihre Veränderung müsse eine äußere Ursache haben: weil im ersteren Falle der Körper nur durch ontologische Prädicate (reine Verstandesbegriffe), z.B. als Substanz, gedacht werden darf, um den Satz a priori zu erkennen; im zweiten aber der empirische Begriff eines Körpers (als eines beweglichen Dinges im Raum) diesem Satze zum Grunde gelegt werden muß, alsdann aber, daß dem Körper das letztere Prädicat (der Bewegung nur durch äußere Ursache) zukomme, völlig a priori eingesehen werden kann [...]." (AA 5: 181).
} 
referida aos conceitos básicos do nosso esquema categorial, apresentados no âmbito metateórico da Analítica dos conceitos ("como substâncias") e dos Princípios (como "substâncias variáveis")? Assim, não parece que possa ser entendida de outro modo senão nos termos de uma ontologia na qual as categorias são criticamente concebidas, no sentido de que não são predicados das coisas em si mesmas, a saber, em abstração do modo como nos são dadas, independente do modo como podemos conhecê-las. Mas isso não significa que essa ontologia não forneça predicados "ontológicos", bem entendidos agora como condições a priori unicamente sob quais "coisas podem se tornar objetos de nosso conhecimento em geral"49. Isso significa que esses predicados, como princípios transcendentais, são os únicos por meio das quais se representa a priori a condição universal pela qual "coisas podem se tornar objetos" Somente porque são a priori pensadas desse modo pelas categorias é que as coisas se tornam objetos (objetos ${ }^{1}$ ), e podem eventualmente se tornar objetos de conhecimento (objetos ${ }^{2}$ ), ou não (obje$\left.\operatorname{tos}^{3}\right)$.

Entretanto, essas não são as únicas passagens onde Kant revela que na Analítica está comprometido com uma nova ontologia. Há muitas outras, sobretudo em suas Reflexionen. Por isso a seguir menciono algumas que me parecem importantes.

Numa Reflexion do início dos anos setenta (Refl. n. 4152, AA17: 436) Kant já dizia que a "Ontologia nada mais é do que uma Lógica transcendental" "51. Essa é quase a mesma relação entre ontologia e lógica transcendental que parecem sugerir um conjunto de Refle-

\footnotetext{
49 "Bedingung a priori vorgestellt wird, unter der allein Dinge Objecte unserer Erkenntniß überhaupt werden können” (AA 5: 181). O grifo é nosso.

50 Ibidem.

51 Neste caso Kant deveria estar pensando na inclusão da Dialética, e não somente da Analítica, já que na primeira se trata da maneira como a ontologia ${ }^{1}$ pode levar a confundir as condições da constituição do pensamento dos objetos com as condições de possibilidade dos objetos da experiência possível (ontologia ${ }^{2}$ ), tomando objetos necessários do pensamento (ideias) como se fossem objetos (objetos ${ }^{3}$ ) do conhecimento. Cf. Refl. n. 5553 (AA18: 222).
} 
xionen datadas entre meados e fins dos anos setenta. Assim, a Refl. n. 5130 sentencia que a ontologia é uma parte da filosofia transcendental (Refl. AA18: 100), e a Refl. n. 5131 define a ontologia como "a ciência dos primeiros conhecimentos do entendi-mento puro: i. dos conceitos, Analítica; 2. dos juízos" (Refl. AA18: 100), claramente ecoando e modificando a definição de Baumgarten ("ciência que contém os primeiros princípios do conhecimento humano") ${ }^{52}$, já que para Kant os "primeiros conhecimentos" do entendimento puro são as categorias (ontologia ${ }^{1}$ ).

Ainda numa outra Reflexion do fim dos setenta e início dos oitenta (Refl. n. 5603), Kant refere que "na ontologia falamos dos conceitos do entendimento cujo uso é possível na experiência, visto que eles próprios (sie selbst) tornam a experiência possível" (Refl. AA18: 247). Ora, se a Refl. n. 5130 e a Refl. n. 5131 sugerem a identificação entre a ontologia e a Analítica, a segunda pareceria incluir mais expressamente a Analítica dos princípios (e a ontologia $^{2}$ ), enquanto que a Refl. n. 5603 parece reforçar a primeira passagem, mas enfatizando as categorias como princípios constitutivos, que tornam possível a experiência (ontologia ${ }^{1}$ e ontolo$g{ }^{2}{ }^{2}$. Todavia, se é verdade que aqui não aparece claramente a ontologia formulada tão explicitamente como uma teoria formal dos objetos, como nas passagens acima citadas da primeira e da terceira Críticas, o que aparece com mais clareza é a ideia de que para Kant a Analítica, como parte da Lógica transcendental, é uma "ontologia". Além disso, considerando que essas Reflexionen são da época na qual Kant está gestando a Crítica da razão pura, parece particularmente importante que estivesse comparando ou identificando sua proposta com as alternativas de sua época a partir do novo ponto de vista crítico. Parece sintomático que Kant continue a

\footnotetext{
52 Já que a ontologia é definida por Baumgarten como a parte da metafísica, ou como metafísica geral, que "est scientia praedicatorum entis generaliorum" que "sunt prima cognitionis humanae principia" (Metaphysica, Editio VII, §§45). Mas Kant costuma corrigir a definição de Baumgarten, aqui como em outras passagens. Cf. Metafísica Dohna, AA28: 615.
} 
aproximar alternativamente a filosofia transcendental, a lógica transcendental ou a Analítica da ontologia. De resto, a aproximação entre Analítica, filosofia transcendental e ontologia reaparece no prefácio dos Progressos (1791):

\begin{abstract}
A ontologia é aquela ciência que (como parte da Metafísica) constitui um sistema de todos os conceitos e princípios do entendimento, mas apenas na medida em que se referem a objetos que podem ser dados aos sentidos e por isso podem ser atestados pela experiência. Não diz respeito ao suprassensível [...] denomina-se filosofia transcendental porque contém a priori as condições e os primeiros elementos de todo o nosso conhecimento. $^{53}$
\end{abstract}

Claramente, Kant relaciona novamente a ontologia, como parte da Metafísica (como metafísica general), à filosofia transcendental, e proscreve-lhe o acesso a entidades suprassensíveis $\left(\right.$ objetos $^{3}$ ), que outrora fora pretensão da Metafísica, transformando-a num sistema que contém como suas partes o que conhecemos como Analítica dos conceitos e Analítica dos princípios. Essa mesma via de reflexão também se vislumbra em muitas outras passagens importantes, em vários manuscritos de cursos transcritos por copistas ou alunos de Kant (Vorlesungen ${ }^{54}$, bem como no próprio manuscrito dos Progressos ${ }^{55}$ e em muitas outras Reflexionen ${ }^{56}$. Todos esses textos, para além das oscilações conceituais e da usual hesitação de Kant no uso de certos termos, à medida que sua reflexão evolui, apontam numa mesma direção. Em primeiro lugar, apontam para

\footnotetext{
53 "Die Ontologie ist diejenige Wissenschaft (als Theil der Metaphysik), welche ein System aller Verstandesbegriffe und Grundsätze, aber nur so fern sie auf Gegenstände gehen, welche den Sinnen gegeben, und also durch Erfahrung belegt werden können, ausmacht. Sie berührt nicht das Übersinnliche [...] und wird Transscendental-Philosophie genannt, weil sie die Bedingungen und ersten Elemente aller unserer Erkenntniß a priori enthält." (AA 20: 260)

${ }^{54}$ Por exemplo, em certas Preleções de Metafísica: AA 28: 616-617 (Dohna); 28: 714 (K2); 28: 185 (L1).

${ }^{55}$ AA 20: 315.

${ }^{56}$ Por exemplo, Refl. n. 5643, n. 5644 etc.; 18: 283-5.
} 
uma ontologia criticamente entendida; em segundo lugar, tendem à identificação entre ontologia e filosofia transcendental, ou entre ontologia e Analítica transcendental. Decerto, mereceriam uma análise e um comentário mais detalhado, que aqui não posso oferecer. No entanto, para finalizar esta justificativa da minha proposta de uma leitura ontológica da Crítica da razão pura e, sobretudo, da Analítica como uma nova ontologia, gostaria de citar mais duas passagens. A primeira é uma interessante Reflexion que parece ser contemporânea da chamada Metafísica Mrongovius (1782-3) ${ }^{57}$ e imputa à ontologia a mesma tarefa que a primeira Crítica atribui à Analítica transcendental:

A ontologia é a ciência das coisas em geral, isto é, da possibilidade do nosso conhecimento das coisas a priori, isto é, independentemente de experiência. Nada nos ensina acerca das coisas em si, mas apenas das condições a priori sob as quais podemos conhecer as coisas na experiência em geral, i.é, [acerca dos] princípios da possibilidade da experiência. $^{58}$

Ora, o que à primeira vista não parece suficientemente claro nesta passagem é em que sentido a ontologia crítica pode ser entendida, ou seja, se como ciência das coisas em geral ou dos princípios da possibilidade de objetos de experiência. Mas podemos pensar que, a princípio, é a ciência das coisas em geral na medida em que fornece os conceitos básicos que se identificam com os objetos em geral, com todos os "objetos" que podemos pensar de alguma forma (onto$\left.\operatorname{logia}^{1}\right)$; e, portanto, são as condições da possibilidade do nosso conhecimento em geral (não apenas de nosso conhecimento empírico). Todavia, esses conceitos de objetos em geral, porque eles são a forma de todo e qualquer "objeto" que podemos pensar, mesmo que seja incognoscível (objetos ${ }^{3}$ ), também constituem a forma de tudo que podemos conhecer empiricamente $\left(\right.$ objetos $\left.^{2}\right)$. Nesse sentido é

${ }^{57}$ AA 29: 747-940.

${ }^{58}$ Refl. n. 5936, AA18: 394. A Refl. está datada em meados e fins dos oitenta. 
que são princípios da possibilidade da experiência como conhecimento empírico (ontologia ${ }^{2}$ ). Isso, por sua vez, é compatível com a segunda passagem, que serviu de epígrafe ao presente estudo. Mormente porque nela aparece explicitamente a relação entre os conceitos de "ontologia" e "objeto":

A ontologia contempla os princípios de cada coisa, [e] portanto, estendese a todas. Tudo que se pode pensar é ou possível ou impossível. O autor [Baumgarten] começa com o possível, mas ele não faz o correto, porque este conceito pode igualmente ser subdividido. O primeiro que é considerado na Metafísica é a palavra objeto, ao qual posteriormente são subordinados todos os outros conceitos. É o conceito universal, supremo na Ontologia. O objeto é possível ou impossível [...]. - A ontologia vai esclarecer os conceitos elementares. ${ }^{59}$

Assim, a ontologia permite pensar todas as coisas, possíveis ou impossíveis, mediante princípios primitivos. O princípio mais primitivo é o conceito de objeto. Portanto, todos os conceitos de objeto que podem ser considerados primitivos ou elementares é que me permitem determinar o possível, o impossível, o cognoscível e o incognoscível. E na Crítica esses conceitos são os conceitos puros do entendimento que Kant apresenta e justifica na Analítica.

\subsection{A estrutura metódica do argumento de Kant na primeira parte da Analítica}

Nessa linha de interpretação, diferente da maioria dos kantianos de língua inglesa, influenciados pela interpretação strawsoniana, com honrosas exceções recentes, penso que a Dedução Metafísica é fundamental ${ }^{60}$. Pois que é nessa seção da primeira Crítica

\footnotetext{
${ }^{59}$ Metafísica Dohna, AA28: 622.

${ }^{60}$ Allison (1983; 2004, p. 134 et seq.); Longuenesse (2005, p. 91 et seq.) e Greenberg (2001, p. 159 et seq.). Mas Longuenesse vem de outra tradição de interpretação franco-alemã, não sofre tanto a influência de Strawson. No continente europeu a coisa é diferente, desde a interpretação de K. Reich (1992; 1932), nos anos trinta, que foi rediscutida recentemente também por M. Wolff (1995) e R. Brandt (1991).
} 
que Kant mostra como da tábua das formas lógicas de julgar se deriva e se apresenta uma tábua de conceitos puros do entendimento como categorias, ou seja, de conceitos puros que possuem um "conteúdo transcendental" (A79/B105), que é resultado do ato espontâneo de nosso pensamento ${ }^{61}$. Por isso não podem ser meras formas lógicas: uma coisa é dizer que são adquiridas e geradas no mesmo ato que produz os juízos, outra que são conceitos puros que representam um conteúdo transcendental. Algo que a mera forma dos juízos por si só não pode ter: a referência a priori a objetos qua objetos em geral.

Assim, Kant ensina que a mesma "função", definida na primeira seção da Analítica dos conceitos como "unidade de ação de ordenar diversas representações sob uma [representação] comum" (A68/B93), aquela pela qual nosso pensamento se refere a objetos mediante os conceitos que aplica em seus juízos (cf. A69/B94), é a que produz a unidade do múltiplo em "conceitos puros de objetos". A mesma função gera tanto a unidade analítica na subsunção de representações num juízo como a "unidade sintética do múltiplo na intuição" (A79 / B105); e esta última é uma unidade produzida a priori, através da qual nossa inteligência se refere a priori a objetos através de conceitos puros simplesmente conectando dados sucessivamente apreendidos na representação unitária de um "ob-

\footnotetext{
${ }^{61}$ Apesar de Longuenesse ser uma das exceções, ao considerar crucial seu papel e de certo modo uma das responsáveis pela valorização dos estudos sobre a Dedução Metafísica na língua inglesa, discordo do modo como parece entender o status das categorias, porque pelo menos na sua formulação de 1998 sugere a ideia de que elas são meras formas lógicas de julgar, ideia que Ralph Walker já defendeu quase trinta anos atrás (1978) e Young depois (1992), confirmando o que considero um preconceito epistêmico. Recentemente ela corrigiu sua formulação, sugerindo que categorias se tornam formas lógicas na sua implementação (2005, p. 105 et seq.), o que não resolve muito a situação porque transmite a ideia de que a tábua das categorias depende da tábua das formas lógicas do juízo, quando na verdade deve ser o contrário, porque as categorias funcionam como princípios e são meta-regras de unidade enquanto funções de síntese do múltiplo das intuições que presidem todo ato de julgar.
} 
jeto", que então a consciência pode reconhecer como tal. Assim, a Dedução metafísica não é tão importante por permitir derivar as categorias a partir da análise das formas lógicas dos juízos, quanto pelo fato de que nos mostra como para entender como pensamos e conhecemos objetos precisamos entender primeiro como julgamos; e mostra como, quando julgamos, já sempre devemos ter produzido uma síntese do múltiplo da intuição, que por sua vez requer um critério não quantitativo de unidade conceitual (B114) que nos permite conduzir todo o múltiplo dado à unidade transcendental da autoconsciência, conferindo-lhe assim a unidade que todo objeto possui. Pois de outro modo eu não conseguiria jamais pensar objetos como "objetos". Por isso Kant vai dizer que as categorias são "conceitos" a priori "de um objeto em geral" (B128).

Isso mostra que enquanto formas do pensamento contêm simultaneamente as condições sob as quais tudo pode ser pensado: o que existe e é real, ou necessário, e o que não existe, mas é possível; ou o que é conhecido negativamente como inexistente, ou ainda, o que se sabe que não se pode pensar positivamente (cf. A96-7). Por isso as categorias constituem em seu conjunto o que chamo de "ontologia"". De fato, somente ao considerar-se que as categorias, enquanto funções de síntese de intuições, são estruturas de objetualidade é que se pode chegar à ideia de que as intuições devem ser necessariamente conforme as categorias, ou que as categorias se referem necessariamente a objetos da intuição enquanto condições de possibilidade de todo conhecimento de objetos, cuja justificação é o afazer principal da Dedução transcendental ${ }^{62}$. É isso o que Kant parece sugerir no $\S 14$ :

\footnotetext{
Uma tábua (das categorias) é derivada analiticamente a partir da outra (a de juízos), mas isso é feito na suposição de que os juízos se fundam nas categorias, e não as categorias nos juízos, não obstante o fato de que o mesmo ato que conduz o múltiplo à unidade da autoconsciência produza ao mesmo tempo a unidade analítica dos conceitos e juízos em juízos e inferências (ii) e a unidade sintética do múltiplo das intuições (i). Justamente porque se trata de resultados do mesmo é que posso derivar uma tábua da outra, que me serve
} 
Com esta condição formal da sensibilidade concordam necessariamente todos os fenômenos porque só aparecem através dela, i.e., podem ser empiricamente intuídos e dados. Ora, pergunta-se se não devem ser precedidos por conceitos a priori como condições unicamente sob as quais algo é, se não intuído, pelo menos pensado como um objeto em geral; porque nesse caso todo o conhecimento empírico dos objetos é necessariamente conforme a esses conceitos, uma vez que sem sua pressuposição nada é possível como objeto de experiência. Ora, toda experiência, além da intuição dos sentidos, através da qual algo é dado, também contém um conceito de um objeto que é dado na intuição ou aparece: portanto, conceitos de objeto em geral deverão subjazer como condições a priori de todo o conhecimento empírico: em consequência, a validade objetiva das categorias como conceitos a priori basear-se-á em que a experiência (de acordo com a forma do pensamento) somente seria possível por meio delas. Assim, então, referem-se necessariamente e a priori a objetos da experiência, porque somente por meio delas [das categorias] pode ser pensado em geral qualquer objeto da experiência. (grifo meu) ${ }^{63}$

de "fio-condutor para a descoberta", mas sem que isso implique fundar categorias na forma lógica dos juízos.

${ }^{62}$ É ao menos o que sugere Kant no $§ 13$ (KrV A89-90/B122-3). Em A parecia ser um pouco diferente: "und Rechfertigung ihrer objektiven Gültigkeit, wenn wir bewiesen können; dass vermittels ihrer allein ein Gegenstand gedacht werden kann" (A96-7).

63 "Mit dieser formalen Bedingung der Sinnlichkeit stimmen also alle Erscheinungen nothwendig überein, weil sie nur durch dieselbe erscheinen, d.i. empirisch angeschauet und gegeben werden können. Nun frägt es sich, ob nicht auch Begriffe a priori vorausgehen, als Bedingungen, unter denen allein etwas, wenn gleich nicht angeschauet, dennoch als Gegenstand überhaupt gedacht wird; denn alsdann ist alle empirische //B126// Erkenntniß der Gegenstände solchen Begriffen nothwendiger Weise gemäß, weil hone deren Voraussetzung nichts als Object der Erfahrung möglich ist. Nun enthält aber alle Erfahrung außer der Anschauung der Sinne, wodurch etwas gegeben wird, noch einen Begriff von einem Gegenstande, der in der Anschauung gegeben wird oder erscheint: demnach werden Begriffe von Gegenständen überhaupt als Bedingungen a priori aller Erfahrungserkenntniß zum Grunde liegen: folglich wird die objective Gültigkeit der Kategorien als Begriffe $a$ priori darauf beruhen, daß durch sie allein Erfahrung (der Form des Denkens nach) möglich sei. Denn alsdann beziehen sie sich nothwendiger Weise und a priori auf Gegenstände der Erfahrung, weil nur vermittelst ihrer überhaupt irgend ein Gegenstand der Erfahrung gedacht werden kann.” (A92-3/B125-6) 
O que mais chama a atenção e parece à primeira vista mais interessante nessa passagem é que as categorias não são apenas consideradas como as condições da possibilidade do conhecimento dos objetos em toda experiência, cuja justificação vai requerer um argumento adicional (a saber, uma dedução transcendental propriamente dita). O que Kant pergunta aqui, primeiro, é se conceitos a priori não deveriam preceder os fenômenos enquanto condições a priori de todo o pensamento dos objetos em geral: "Nun frägt es sich, ob nicht auch Begriffe a priori vorausgehen, als Bedingungen, unter denen allein etwas, wenn gleich nicht angeschauet, dennoch als Gegenstand überhaupt gedacht wird" (ibidem). Pois nesse caso seria possível ponderar a possibilidade de que todo conhecimento fosse sujeito a essas condições: como todo conhecimento (como espécie) supõe o pensamento (como gênero), todo conhecimento de um objeto supõe já que o objeto possa ser, antes de tudo, pelo menos pensado como tal. Numa palavra: se pode ser conhecido como objeto de experiência tem que poder ser pensado mediante conceitos de objeto. Não pode ser objeto de experiência se não é pensado primeiro como "objeto": "denn alsdann ist alle empirische Erkenntniß der Gegenstände solchen Begriffen nothwendiger Weise gemäß, weil ohne deren Voraussetzung nichts als Object der Erfahrung möglich ist" (ibidem). Assim, à sua própria pergunta Kant responde então que como toda experiência de objetos inclui não somente uma intuição, mas também conceitos de objeto, é preciso que os conceitos de objeto em general estejam no fundamento de toda a experiência como suas condições: "Nun enthält aber alle Erfahrung außer der Anschauung der Sinne, wodurch etwas gegeben wird, noch einen Begriff von einem Gegenstande, der in der Anschauung gegeben wird oder erscheint: demnach werden Begriffe von Gegenständen überhaupt als Bedingungen a priori aller Erfahrungserkenntniß zum Grunde liegen" (ibidem).

Neste sentido fica claro por que Kant chama as categorias de predicados ontológicos, visto que nada pode ser pensado sem elas, 
nada pode ser a priori um ente, ou uma propriedade, ou uma relação, a não ser como "objeto", com base e por meio das categorias. Tudo que é possível pensar, independente de existir ou não existir fora do pensamento, ou de se decidir se existe ou não, tem que ser pensado a priori com elas e por meio delas. Aliás, essa é de certo modo a complicação que conduz a metafísica wolfiana a confundir os predicados do pensar (objetos ${ }^{1}$ ) com entidades ou predicados noumenais $\left(\right.$ objetos $^{3}$ ), e é por isso que a Dedução Metafísica vai precisar do complemento de uma Dedução transcendental: para mostrar que estes predicados ontológicos possuem uma finalidade e um campo de aplicação bem mais específico $\left(\right.$ objetos $\left.^{2}\right)$.

Em consequência, se tivesse que resumir minha ideia central sobre o papel da Dedução Metafísica e sua relação com a Dedução transcendental, diria que na minha interpretação da estrutura metódica da Analítica a primeira estabelece uma tábua categorial como um conjunto de conceitos puros de objetos em geral a partir da análise do conceito de função; e então demonstra que esses conceitos são as condições da possibilidade de todo e qualquer pensamento de objetos (ontologia ${ }^{1}$ ), e por isso mesmo da objetualidade dos objetos enquanto tais; enquanto que a segunda tenta demonstrar que essas mesmas condições são as condições de possibilidade de todo e qualquer conhecimento de objetos a partir da análise do conceito de uma consciência empírica de ter percepções $^{64}$. O resultado dessa análise, como se sabe, é tal que as condições do pensamento coincidem com as do conhecimento; mas isso ocorre se (e somente se) se restringe o âmbito de seu uso ao que pode ser percebido. Nesse caso, as "condições de possibilidade da experiência em geral são ao mesmo tempo as condições de possibilidade dos objetos da experiência" (A158/B197). Com efeito, não pode haver experiência que não seja experiência de objetos, e não pode haver experiência de objetos se não houver primeiro "objetos".

\footnotetext{
${ }^{64}$ Aqui penso em B132-133. Tratei disso em Bonaccini (2006). Na primeira edição as coisas parecem ligeiramente diferentes. Cf. A107-109.
} 
Todavia, a Dedução apresenta em termos gerais um argumento que restringe o uso das categorias como conceitos de (objetos ${ }^{1}$ ) a um contexto de aplicação temporal de $\left(\right.$ objetos $\left.^{2}\right)$, mas que deve ser especificado. Por isso, como muitos intérpretes já notaram, é complementado e especificado nos capítulos do Esquematismo e dos Princípios, especialmente nos princípios da relação. Analogamente ao modo como a segunda parte da Dedução transcendental especifica e estende a princípio a validade objetiva das categorias a todos os objetos da intuição empírica (a primeira parte estabelecia sua validade em princípio apenas para um múltiplo da intuição sensível em geral ${ }^{65}$, o Esquematismo explica como é possível que estruturas a priori unitárias como os conceitos puros do entendimento sejam aplicáveis a fenômenos espáciotemporais, que envolvem sempre uma multiplidade empírica aparentemente incomensurável. Assim, os Princípios especificam cada caso, formulando e justificando os juízos nos quais ocorrem as categorias já esquematizadas (i.e., já referidas a um domínio temporal). Mas somente os da relação garantem a realização plena das categorias esquematizadas como condições de possibilidade dos objetos da experiência, a saber, constituídas a priori como substâncias espáciotemporais que interagem de acordo com leis causais.

\subsection{Categorias, esquemas e analogias}

Ora, se consideramos as Analogias da experiência sob este ponto de vista, antes de entendê-los como meros princípios epistemológicos ou regras semânticas que a priori regulariam a investigação empírica devemos lembrar que contêm os esquemas das categorias da relação. Nesse sentido, são formulações proposicionais de categorias esquematizadas que fornecem a priori não somente as condições da verdade como também e, sobretudo, a estrutura a priori dos próprios objetos da experiência em geral enquanto substâncias atuais ou possíveis; quer dizer, como substâncias espáciotemporais

${ }^{65}$ Cf. Caimi, 2007, p. 99 et seq. 
que podem interagir causalmente entre si. No capítulo das Analogias Kant descreve os princípios da relação e justifica seu caráter ontológico enquanto princípios da determinação objetiva dos fenômenos no tempo (objetos ${ }^{2}$ ) e, por conseguinte, da possibilidade da experiência. Assim, não deveriam ser considerados como princípios meramente epistemológicos (quer semânticos, quer não) porque são também, sobretudo, ontológicos: trata-se de princípios constitutivos da possibilidade da experiência ${ }^{66}$.

Una razão aparente contra minha posição é o fato de que Kant por vezes se refere às Analogias como princípios "regulativos" da percepção, em contraste com os Axiomas e as Antecipações (A179 et seq./B222 et seq.). Mas vale lembrar que devem ser considerados como constitutivos da experiência ${ }^{67}$. Por conterem os esquemas das categorias da relação (A135 et seq./B174 et seq.) permitem explicar como reportamos categorias (a saber, estruturas lógicotranscendentais do entendimento) aos fenômenos espáciotemporais como objetos da experiência (A138/B177) ${ }^{68}$. Desse modo, ain-

\footnotetext{
${ }^{66}$ Apesar de ir contra uma tradição de interpretação que remonta ao neokantismo do Século XIX (Laass, 1876, p. 2 et seq./53 et seq.) e interpreta as Analogias como princípios epistemológicos, penso que é preciso mostrar o aspecto ontológico negligenciado no neokantismo e na maioria das interpretações em voga.

${ }^{67}$ A qual não se identifica com a "percepção", na medida em que a experiência consiste numa conexão de percepções. Cf. KrV B12; B219 et seq. Cf. A156-7/ B195.

${ }^{68}$ Por isso não podem ser entendidas apenas como regras de orientação para a pesquisa empírica (Loparić, 2000, p. 186/273), uma vez que aquilo que Kant diz em A156-7/B195-6 aplica-se a todos os quatro tipos dos princípios, incluindo as Analogias: "Die Möglichkeit der Erfahrung ist also das, was allen unsern Erkenntnissen a priori objective Realität giebt. Nun beruht Erfahrung auf der synthetischen Einheit der Erscheinungen, d.i. auf einer Synthesis nach Begriffen vom Gegenstande der Erscheinungen überhaupt, ohne welche sie nicht einmal Erkenntniß, sondern eine Rhapsodie von Wahrnehmungen sein würde, die sich in keinem Context nach Regeln eines durchgängig verknüpften (möglichen) Bewußtseins, mithin auch nicht zur transscendentalen und nothwendigen Einheit der Apperception zusammen schicken würden. Die Erfahrung hat also Principien ihrer Form a priori zum Grunde liegen, nämlich allge-
} 
da que no contexto em questão elas sejam definidos como princípios regulativos, enquanto regras de unificação de percepções ("Bedingungen der notwendigen Vereinigung aller Wahrnemungen in einer Erfahrung"), são na verdade o que permite constituir a priori um mundo empírico de objetos que existem no espaço e no tempo; que possuem propriedades e mantêm relações causais entre si (Cf., por exemplo, A664/B692). Assim, como condições da unificação necessária das nossas percepções numa experiência, produzem a priori uma unidade sem a qual não podemos conhecer qualquer objeto do mundo sensível ${ }^{69}$.

meine Regeln der Einheit in der Synthesis der Erscheinungen, deren objective Realität als nothwendige Bedingungen jederzeit in der Erfahrung, ja sogar ihrer Möglichkeit gewiesen werden kann. Außer dieser Beziehung aber sind synthetische Sätze $a$ priori gänzlich unmöglich, weil sie kein Drittes, nämlich keinen Gegenstand haben, an dem die synthetische Einheit ihrer Begriffe objective Realität darthun könnte".

${ }^{69}$ A216/B263. Cf. Prolegomena, §36: "Die Möglichkeit der Erfahrung überhaupt ist also zugleich das allgemeine Gesetz der Natur, und die Grundsätze der erstern sind selbst die Gesetze der letztern. Denn wir kennen Natur nicht anders als den Inbegriff der Erscheinungen, d.i. der Vorstellungen in uns, und können daher das Gesetz ihrer Verknüpfung nirgend anders als von den Grundsätzen der Verknüpfung derselben in uns, d.i. den Bedingungen der nothwendigen Vereinigung in einem Bewußtsein, welche die Möglichkeit der Erfahrung ausmacht, hernehmen. [...] Wir müssen aber empirische Gesetze der Natur, die jederzeit besondere Wahrnehmungen voraussetzen, von den reinen oder allgemeinen Naturgesetzen, welche, ohne daß besondere Wahrnehmungen zum Grunde liegen, blos die Bedingungen ihrer nothwendigen Vereinigung in einer Erfahrung enthalten, unterscheiden; und in Ansehung der letztern ist Natur und mögliche Erfahrung ganz und gar einerlei [...]" (Ak. IV: 319-320). Comentando o problema das Analogias à luz dessa passagem, Lass lembra que a questão das Analogias é a da possibilidade da experiência, "von Inbegriff von den Regeln, von 'reinen und allgemeinen Naturgesetzen' [...] unter denen alle Erscheinungen stehen müssen [...]. Die eigenthümlich Kantische [...] als 'anfangs befremdlich' bezeichnete Antwort ist bekanntlich: Sie sind 'möglich', sie haben nicht bloss apriorischen Ursprung, sondern auch apriorische Gültigkeit, weil 'der Verstand seine Gesetze (a priori) nicht aus der Natur schöpft, sondern sie dieser vorschreibt', weil 'Natur und mögliche Erfahrung ganz und gar einerlei ist'; weil jene Gesetze die 'Bedingungen der 
Com efeito, a partir da afeç̧ão (A19/B33) a sensibilidade recebe os dados sensoriais como uma série apreendida sucessivamente, sintetizada pela imaginação e compreendida através da unificação operada pelas categorias como sendo uma série de percepções de objetos empíricos no espaço e no tempo (A98-9; B160-1), unificação essa que não seria possível, segundo Kant, senão a partir da mediação dos esquemas ${ }^{70}$.

Nesse sentido, do ponto de vista da "linguagem-objeto" que codifica e constitui nossa experiência e serve de ponto de partida da análise (A1-2/B1-2) as Analogias não podem ser consideradas como sendo meros princípios orientadores, ou critérios de identificação na pesquisa empírica; justamente porque contêm os "esquemas" da relação. Isso é geralmente entendido na medida em que são princípios dinâmicos regulativos, e não constitutivos como os princípios matemáticos. Na verdade, a função das Analogias somente é definida como regulativa num plano metalinguístico, entendidas como proposições sintéticas a priori que enunciam os princípios da possibilidade da experiência enquanto suas regras de identificação e reidentificação de objetos ("Substâncias"), de rela-

notwendigen Vereinigung aller Wahrnemungen in einer Erfahrung' enthalten, 'ohne welche wir ganz und gar keinen Gegenstand der Sinnenwelt erkennen können'. Mit dieser höchsten Aufgabe der Transcendentalphilosophie nun stehen unsere Analogien im unauflöslichen Zusammenhang [...]." (1876, p. 10-11).

70 "Die Grundsätze des reinen Verstandes, sie mögen nun a priori constitutiv sein (wie die mathematischen), oder bloß regulativ (wie die dynamischen), enthalten nichts als gleichsam nur das reine Schema zur möglichen Erfahrung; denn diese hat ihre Einheit nur von der synthetischen Einheit, welche der Verstand der Synthesis der Einbildungskraft in Beziehung auf die Apperception ursprünglich und von selbst ertheilt, und auf welche die Erscheinungen, als data zu einem möglichen Erkenntnisse, schon a priori in Beziehung und Einstimmung stehen müssen. Ob nun aber gleich diese Verstandesregeln nicht allein a priori wahr sind, sondern sogar der Quell aller Wahrheit, d.i. der Übereinstimmung unserer Erkenntniß mit Objecten, dadurch daß sie den Grund der Möglichkeit der Erfahrung als des Inbegriffes aller Erkenntniß, darin uns Objecte gegeben werden mögen [...]." (A237/B296) 
ções de causa e efeito ("Causalidade"), e de relações de interação causal ("Comunidade"). Portanto, num nível semântico mais elevado que o da primeira ordem de predicados; a saber, do ponto de vista do plano resultante da reflexão crítica sobre as condições de possibilidade da experiência a partir do que num plano de primeira ordem funciona como uma espécie de linguagem-objeto, que Kant denomina às vezes "experiência", no sentido do que é basicamente "dado" do ponto de vista do que ele chama a matéria dos fenômenos (A20/B34). Todavia, enquanto contêm categorias esquematizadas em juízos sintéticos a priori as Analogias operam como princípios da possibilidade da experiência; nessa medida, têm que ser constitutivas. Isso significa que a distinção entre "constitutivo e "regulativo" aplicada aos princípios do entendimento puro não pode ser entendida como sinônimo da distinção entre "categorias" (constitutivas) e "ideias" (regulativas). Quando Kant diz em B221 que as Antecipações e os Axiomas devem ser entendidos como princípios matemáticos e "constitutivos" da nossa percepção, enquanto que as Analogias e os Postulados devem ser entendidos como princípios "regulativos", "regulativo" não pode significar aqui o mesmo que quando o termo é referido ao uso regulativo das ideias. Aqui se trata de uma distinção feita no interior do conceito de categoria como princípio constitutivo da possibilidade dos objetos da experiência enquanto tal. Portanto, as Analogias são regulativas, por oposição aos princípios matemáticos, apenas no sentido de que os estes abstraem da existência ou inexistência dos objetos, e na medida em que elas se referem a priori aos objetos da experiência, cuja existência que deve ser dada e atestada em cada caso (e não pode ser conhecida a priori). Nesse sentido, são regulativas em relação à intuição, como diz o próprio Kant no Apêndice, mas constitutivas em relação à experiência:

Na Analítica transcendental distinguimos entre os princípios do entendimento os princípios dinâmicos, enquanto simplesmente regulativos da intuição, dos matemáticos que, em relação a esta última, são constitutivos. Não obstante esta distinção, as mencionadas leis dinâmicas são, 
todavia absolutamente constitutivas em relação à experiência, na medida em que possibilitam a priori os conceitos sem os quais não há experiência. Em contrapartida, os princípios da razão pura, em relação aos conceitos empíricos, nunca podem ser constitutivos, porque não pode dar-se-lhes nenhum esquema correspondente da sensibilidade e não podem, por conseguinte, ter nenhum objeto in concreto. Se renuncio ao uso empírico desses princípios, como princípios constitutivos, como posso querer assegurar-lhes um uso regulativo acompanhado de validade objetiva, e que significado poderá ter esse uso ${ }^{71}$

Por isso, enquanto princípios constitutivos da possibilidade da experiência, as "Analogias da experiência" nos permitem pensar e conhecer a priori a estrutura dos objetos como substâncias permanentes e seus estados objetivos de ação e/ou interação causais. Somente nessa medida oferecem uma regra para distingui-los de nossos estados de consciência subjetivos no todo da experiência. Aqui o conceito de analogia nos permite esquematizar a priori a estrutura lógico-ontológica da experiência dada pelas categorias enquanto experiência de (objetos ${ }^{2}$ ) e suas relações em analogia com os modos temporais de duração, sucessão, e simultaneidade ${ }^{72}$. As-

\footnotetext{
71 "Wir haben in der transscendentalen Analytik unter den Grundsätzen des Verstandes die dynamische, als bloß regulative Principien der Anschauung, von den mathematischen, die in Ansehung der letzteren constitutiv sind, unterschieden. Diesem ungeachtet sind gedachte dynamische Gesetze allerdings constitutiv in Ansehung der Erfahrung, indem sie die Begriffe, hone welche keine Erfahrung stattfindet, a priori möglich machen. Principien der reinen Vernunft können dagegen nicht einmal in Ansehung der empirischen Begriffe constitutiv sein, weil ihnen kein correspondirendes Schema der Sinnlichkeit gegeben werden kann, und sie also keinen Gegenstand in concreto haben können. Wenn ich nun von einem solchen empirischen Gebrauch derselben als constitutiver Grundsätze abgehe, wie will ich ihnen dennoch einen regulativen Gebrauch und mit demselben einige objective Gültigkeit sichern, und was kann derselbe für Bedeutung haben?” (A664/B692)

${ }^{72}$ Bonaccini (2013c, p. 37 et seq.). Nem todo mundo entende dessa maneira o uso do termo no contexto das "Analogias da experiência". Dar uma ilustração do modo como os intérpretes tratam das Analogias, porém, não é fácil; a quantidade de trabalhos é imensurável. Mas a maioria concentra-se no mais das vezes nos argumentos; não no uso do conceito de "analogia". Para ter uma
} 
sim, dizer que as Analogias da experiência são "analogias" significa dizer que tais princípios são pensados a priori por analogia com os predicados básicos da temporalidade que é constitutiva da nossa percepção e experiência do mundo. Mas essa noção de "analogia” é pelo menos parcialmente dependente de uma definição que Kant oferece logo no início da introdução das Analogias, como certa semelhança entre relações cujos termos são distintos.

Outra razão pela qual se tende a rejeitar a tese de que os princípios contidos no capítulo sobre analogias são ontológicos baseia-se naquela outra passagem da Crítica que mencionei anteriormente: Kant teria dito que o nome orgulhoso de "ontologia" devia dar lugar ao nome mais modesto de uma Analítica do entendimento (KrV A247/B303). Mas muitas vezes é esquecido que aqui Kant se refere à ontologia racionalista dogmática e que em lugar algum está escrito que o termo não pode ter uma aplicação no domínio da filosofia crítica. Como sugeri antes, há muitos lugares nos quais Kant usa o termo "ontologia" em um sentido crítico, mesmo na Crítica da razão pura. Além disso, ao negar-se o aspecto essencialmente ontológico das categorias e princípios supõe-se tacitamente que o uso do termo "ontologia" e seus derivados ("ontológica" etc.) aplica-se apenas no contexto da metáfora do dogmático ou pré-crítico. Porém, o fato de que Kant tenha criticado certo uso do conceito não implica necessariamente que ele não tenha outra utilização legítima e coerente com a proposta de uma metafísica crítica da natureza, como Kant a denomina por vezes, e que a meu ver nada é senão o que hoje chamamos de "teoria dos objetos", ou seja, uma meta-teoria que explica e justifica categorias a priori como formas constitutivas dos objetos em geral e meta-conceitos

ideia de alguns trabalhos já clássicos, veja-se, a título de exemplo, Strawson (1966, p. 122 et seq.), Melnick (1973, sobretudo p. 50 et seq.), Allison (1983, p. 199 et seq.), Guyer (1987, p. 207 et seq.), Van Cleve (1999, p. 106 et seq./ 128 et seq.). Há outros interessantes e mais recentes como o recente livro de G. Bird (2006, p. 389 et seq.). 
de objeto em geral, permitindo construir a priori a forma dos "objetos" atuais e possíveis que povoam nosso universo.

\section{3. À guisa de conclusão}

Conforme defendi acima e em trabalhos anteriores (Bonaccini 2012; 2013a; 2013b; 2013c), se minha reconstrução do estatuto e da estrutura metódica da Analítica funciona minimamente as categorias, tomadas per se, devem ser consideradas como conceitos estruturais de objetos qua objetos (ontologia ${ }^{1}$ ) e sem elas jamais poderíamos sequer pensar ou conhecer este mundo como um mundo de objetos espáciotemporais que têm propriedades e relações causais (ontologia ${ }^{2}$ ). As analogias, por sua vez, representam o corpo explicativo do argumento crítico princípios metateóricos que expressam as categorias esquematizadas de substância, causalidade e interação causal. Por isso não devem ser consideradas apenas como regras epistêmicas, ou mesmo como princípios meramente semânticos, mas como princípios ontológicos, na medida em que são princípios a priori que constituem a possibilidade da experiência mesma de um mundo de (objetos ${ }^{2}$ ) e permitem formular os critérios que proscrevem a pretensão da metafísica tradicional ao conhecimento de (objetos ${ }^{3}$ ). São, além disso, os únicos critérios a que temos acesso para conhecer e distinguir o existente do inexistente, o possível do impossível, mesmo aquilo que em princípio é conhecido como possivelmente existente. Por conseguinte, somente na medida em que são referidas ao tempo é que as categorias puras podem oferecer a estrutura ontológica de todo objeto e de todo o estado de coisas possível na experiência (os objetos ${ }^{2}$ da onto$\operatorname{logia}^{2}$ ). Somente então é que podem envolver uma semântica e ser tomadas como princípios de significação das proposições num domínio de objetos em que os problemas posto pela razão são solúveis; e ainda podem servir de critérios justificação de pretensões de conhecimento.

Finalmente, penso que o modo como Kant estabelece uma analogia comparando as relações temporais de duração, sucessão e 
simultaneidade com as relações entre objetos e estados de coisas parece muito promissor para os esforços de hoje em ontologia e epistemologia. Por exemplo, podemos pensar objetos abstratos como predicados de n-ordens, por analogia com objetos temporais concretos cuja representação pode ser estipulada como a de objetos abstratos atemporais. Mas esse uso do conceito de analogia é o tema de outro trabalho (2013c; 2014).

\section{Referências}

\section{Fontes}

BAUMGARTEN, Alexander Gottlieb (1739), Metaphysica. 4. ed. Halle: Carl Hemmerde, 1757. 432 p. [Outras edições: $2^{\mathrm{a}}$. 1743 (363 p.), $3^{\mathrm{a}}$. 1750 (387 p.), 4 1757 (432 p.), 5 a 1763 (432 p.), 6 .1768 (432 p.), $7^{\mathrm{a}} .1779$ (432 p.). Impressão fac-símile da $7^{\mathrm{a}}$. ed. Hildesheim, Georg Olms, 1963 (xlvii, 432 p., incluindo index, synopses e prefácios das três primeiras edições)].

KANT, Immanuel. Kritik der reinen Vernunft. Nach der ersten und zweiten Original-Ausgabe neu herausgegeben von Raymund Schmidt. Hamburg: F. Meiner, 1956. (Durchgesehener Nachdruck von 1976.)

KANT, Immanuel. Kant's gesammelte Schriften. Hrsg. von der Preussischen und ihren Nachfolgern (Deutschen/Göttingischen) Akademie der Wissenschaften. Berlin: G. Reimer; W. de Gruyter, 1902-.

\section{Literatura secundária}

ABELA, P. Kant's empirical realism. Oxford: Oxford Clarendon Press, 2003.

ALLISON, H. E. Kant's transcendental idealism: an interpretation and defense. New Haven; London: Yale University Press, 1983.

ALLISON, H. E. Idealism and freedom, Cambridge: Cambridge University Press, 1996. 
ALLISON, H. E. Kant's transcendental idealism. Revised and Enlarged Edition. New Haven; London: Yale University Press, 2004.

ALMEIDA, G. A. Self-consciousness and objective knowledge in the Transcendental Deduction of the Critique of Pure Reason. In: RAUSCHER, F.; PÉREZ, D. (Ed.). Kant in Brazil. Rochester: University of Rochester Press, 2012. p. 26-55.

AMERIKS, K. Kant's theory of mind: an analysis of the paralogisms of pure reason. Oxford: Clarendon Press, 1982; New edition, 2000.

AMERIKS, K. The critique of metaphysics: Kant and traditional ontology. In: GUYER, Paul. (Ed.). The Cambridge companion to Kant. Cambridge: Cambridge University Press, 1992. p. 249-271.

AMERIKS, K. Interpreting Kant's Critiques. Oxford: Oxford University Press, 2003.

AQUILA, R. E. Representational mind: a study of Kant's theory of knowledge. Bloomington: Indiana University Press, 1983. (Studies in Phenomenology and Existencial Philosophy).

ARRAIS, L. A. Cisneiros. O eu e o infinito: da crítica kantiana à semântica da ontologia clássica e de suas implicações sobre o problema da subjetividade. Recife: UFPE, 2001. 257 p.

AZEVEDO MARQUES, U. R de. Kant e a epigênese a propósito do "inato". Scientiæ Studia. São Paulo, v. 5, n. 4, 2007, p. 453-470.

AZEVEDO MARQUES, U. R de. Sobre o "inato" em Kant. Analytica. Rio de Janeiro, v. 12, n. 2, 2008, p. 101-161.

AZEVEDO MARQUES, U. R de. Bemerkungen über die Kant-Forschung in Brasilien. Kant-Studien, v. 100, n. 3, 2009, p. 369-378.

BECK, L. W. Essays on Kant and Hume. New Haven; London: Yale University Press, 1978. 
BENNET, J. Kant's Analytic. Cambridge: Cambridge University Press, 1966.

BIRD, G. The revolutionary Kant: a commentary on the Critique of pure reason, Chicago; La Salle: Open Court, 2006.

BONACCINI, J. A. O conceito de coisa em si no Idealismo Alemão. Tese (Doutorado em Filosofia) - Instituto de Filosofia e Ciências Sociais, Universidade Federal do Rio de Janeiro. Rio de Janeiro, 1997. 368 p.

BONACCINI, J. A. Kant e o problema da coisa em si no Idealismo Alemão: sua atualidade e relevância para a compreensão do problema da filosofia. Rio de Janeiro: Relume Dumará, 2003.

BONACCINI, J. A. El problema de la identidad personal en la primera parte de la Deducción B. Revista Latinoamericana de Filosofia, Buenos Aires, Vol. XXXII, n. 1, 2006, p. 37-71.

BONACCINI, J. A. O argumento da Estética e o problema da aprioridade: ensaio de um comentário preliminar. In: KLEIN, J. T. (Org.). Comentários às obras de Kant: Crítica da razão pura, Florianópolis: UFSC/NEFIPOn line, 2012, p. 71-144. Disponível em:

< http://www.nefipo.ufsc.br/files/2012/11/comentarios1.pdf > . Acesso em: 21 ago. 2016.

BONACCINI, J. A. Sobre o projeto kantiano de uma Filosofia Transcendental. Educação e Filosofia. Uberlândia, vol. 27, n. esp., 2013[a], p. 211-232.

BONACCINI, J. A. Kant's theory of objects. In: CONGRESSO Interamericano de Filosofía, 17. Salvador, 7 a 11 out. 2013[b]. (inédito).

BONACCINI, J. A. On Kant's concept of analogy. In: BACIN, S.; FERRARIN, A.; LA ROCCA, C.; RUFFING, M. (Ed.). Kant und die Philosophie in weltbürgerlicher Absicht - Akten des XI. Kant-Kongresses 2010. Berlin: W. de Gruyter, 2013c. v. 2, p. 37-52. 
BONACCINI, J. A. Esquema, símbolo e analogia. In: BONACCINI, J. A.; PRINGE, H. (Org.). Esquematismo e analogia: ensaios sobre a metafísica de Kant. [2014]. (inédito).

BONACCINI, J. A. Ontología, epistemología y semántica: sobre la teoría kantiana acerca de la estructura objectual del mundo. In: JÁUREGUI, C.; PRINGE, H.; MOLEDO, F.; THISTED, M. (Ed.). Crítica y metafísica:

Festschrift en homenaje a Mario Caimi. Hildesheim: Olms, 2015. p. 27-46.

BRANDT, R. Die Urteilstafel: Kritik der reinen Vernunft A 67-76; B 92-101. Kant-Forschungen 3. Hamburg: F. Meiner, 1991.

BRUECKNER, Anthony. Transcendental arguments I. Noûs, 17, 1983, p. 551-576.

BRUECKNER, Anthony. Transcendental arguments II. Noûs, 18, 1984, p. 197-225.

CABRERA, J. Posibilidad del lenguaje metafísico: del programa kantiano de 1783 al moderno apriorismo pluralista. Revista Latinoamericana de filosofía. Buenos Aires, Vol. XI, n. 1, 1985.

CAIMI, M. La metafísica de Kant. Buenos Aires: EUDEBA, 1989.

CAIMI, M. Kants Metaphysik: zu Kants Entwurf einer metaphysica specialis. In: von FUNKE, G. (Ed.). Akten des Siebenten Internationalen Kant-Kongresses - Kurfürstliches Schloß zu Mainz, 1990. Bonn: Bouvier, 1991. p. 103-126.

CAIMI, M. Consideraciones acerca de la metafísica de Kant. Revista Latinoamericana de Filosofía. Buenos Aires, Vol. XVIII, n. 2, 1992, p. 259286.

CAIMI, M. Leçons sur Kant: la déduction transcendantale dans la deuxiène édition de la Critique de la raison pure. Paris: Publications de la Sorbonne, 2007. 
CAIMI, M. Application of the Doctrine of Method in the critical examination of reason. Studia Kantiana. Rio de Janeiro, 13, 2012, p. 516.

CASSAM, Q. Transcendental arguments, transcendental synthesis and transcendental idealism. Philosophical Quarterly, 37. 1987

CHENET, F. X. L'assise de l'ontologie critique: l'Esthétique transcendantale. Lille: Presses Universitaires de Lille, 1994.

CHIBA, K. Kants Ontologie der raumzeitlichen Wirklichkeit: versuch einer anti-realistischen Interpretation der Kritik der reinen Vernunft. Berlin: W. de Gruyter, 2012.

COFFA, J. A. The semantic tradition from Kant to Carnap: to the Vienna station. New York: Cambridge University Press, 1991.

DALBOSCO, C. A. O idealismo transcendental de Kant. Passo Fundo: EDIUPF, 1997.

DALBOSCO, C. A. Idealismo transcendental e ontologia. In: CENCI, A. V. (Org.). Temas sobre Kant: Metafísica, Estética e Filosofia Política. Porto Alegre: Edipucrs, 2000. p. 7-23. (Coleção Filosofia, n. 106).

DICKER, G. Kant's theory of knowledge. New York: Oxford University Press, 2004.

FICARA, E. Die Ontologie in der Kritik der reinen Vernunft. Würzburg: Königshausen und Neumann, 2006.

FIGUEIREDO, V. B. de. Kant e a Crítica da razão pura. Rio de Janeiro: Zahar, 2005.

FREULER, L. Kant et la métaphysique spéculative. Paris: Vrin, 1992.

GENOVA, A. C. Good transcendental arguments. Kant-Studien, 75, 1984, p. 469-495. 
GREENBERG, R. Kant's theory of a priory knowledge. Pensilvania:

Pensilvania State University Press, 2001.

GUYER, P. Kant and the claims of knowledge. Cambridge: Cambridge University Press, 1987.

GUYER, Paul. Kant. London; New York: Routledge, 2006.

HAHMANN, A. Kritische Metaphysik der Substanz: Kant im Widerspruch zu Leibniz. Berlin: W. de Gruyter, 2009.

HANNA, R. Kant and the foundations of analytic philosophy. Clarendon: Oxford Univiversity Press, 2001.

HEIDEGGER, M. Sein und Zeit. Tübingen: Niemeyer, 1927.

HEIDEGGER, M. Kant und das Problem der Metaphysik. Frankfurt am Main: V. Klostermann, 1929. [4. Auflage, 1973]

HEIDEGGER, M. Die Frage nach dem Ding: zu Kants Lehre von den transzendentalen Grundsatzen [Freiburger Vorlesung, Wintersemester 1935-36]. Hrsg. von P. Jaeger. Frankfurt am Main: V. Klostermann, 1984. (Gesamtausgabe, Band 41).

HEIMSOETH, H. Studien zur Philosophie Immanuel Kants. Metaphysische Ursprünge und ontologische Grundlagen, Köln: Kölner-Universitäts-Verlag, 1956.

HOGREBE, W. Kant und das Problem einer transzendentaler Semantik. Freiburg; München: K. Alber, 1974; 1977.

KITCHER, P. Kant's transcendental psychology. Oxford: Oxford University Press, 1990.

KLEIN, J. T. (Org.). Comentários às Obras de Kant: Crítica da razão pura, Comentários às obras de Kant: Crítica da razão pura, Florianópolis: UFSC/NEFIPOn line, 2012. Disponível em: 
< http://www.nefipo.ufsc.br/files/2012/11/comentarios1.pdf > . Acesso em: 21 ago. 2016.

KÖRNER, Stephan. Categorial Frameworks. Oxford: B. Blackwell, 1974.

LAASS, E. Kants Analogien der Erfahrung. Berlin: Weidmann, 1876.

LEBRUN, G. Kant et la fin de la métaphysique. Paris: A. Colin, 1970. [Trad. brasileira: C. A. Ribeiro de Moura. São Paulo: M. Fontes, 1993].

LICHT DOS SANTOS, P. R. A dedução transcendental e o idealismo crítico. Dissertação (Mestrado em Filosofia) - Universidade de São Paulo. São Paulo, 1997. 203 p.

LONGUENESSE, B. Kant and the capacity to judge: sensibility and discursivity in the Transcendental Analytic of the Critique of Pure Reason. Transl. Charles T. Wolfe. New Jersey: Princeton University Press, 1998.

LONGUENESSE, B. Kant on the human point of view. Cambridge: Cambridge University Press, 2005.

LOPARIĆ, Z. A semântica transcendental de Kant. 2. ed. Campinas: EDUNICAMP/Centro de Lógica, Epistemologia e História da Ciência, 2000.

LOUX, M. Introduction to Metaphysics: a contemporary introduction. 2. ed. London: Routledge, 2002.

LOUX, M.; ZIMMERMANN, D. (Ed.). The Oxford handbook of Metaphysics. Oxford; New York: Oxford University Press, 2003.

MARTIN, G. Immanuel Kant: Ontologie und Wissenschaftstheorie. Köln: Kölner Universitätsverlag, 1951. [4. durchgesehene und um einen dritten Teil vermehrte Auflage. Berlin: W. de Gruyter, 1969].

MELNICK, A. Kant's analogies of experience. Chicago: University of Chicago Press, 1973. 
OBERHAUSEN, M. Das neue a priori: Kants Lehre von einer 'ursprünglichen Erwerbung' apriorischer Vorstellungen. Stuttgart-Bad Cannstatt:

Frommann-Holzboog, 1997.

PATON, H. J. Kant's metaphysic of experience. 2. ed. New York:

Macmillan, 1951 [1936]. 2. v.

PAULSEN, F. Immanuel Kant: sein Leben und seine Lehre. 2. und 3. Auflage. Stuttgart: Frommann, 1899.

PÉREZ, D. O. A Semântica transcendental de Kant. Resenha de: LOPARIĆ, Z. A semântica transcendental de Kant. 2. ed. Revista de Filosofia. Curitiba, v. 15 , n. 16 , jan.-jun. 2003, p. 87-88.

PÉREZ,, D. O. (Org.). Kant no Brasil. São Paulo: Escuta, 2005. (Coleção Filosofia no Brasil).

PÉREZ, D. O. Kant e o problema da significação. Curitiba:

Champagnat, 2008.

PÉREZ, D. O.; BONACCINI, J. A. On Kantian studies and Kant's influence in Brazil. Kant e-Prints. Campinas, Série 2, v. 4, n. 1, 2009, p. 23-41.

PÉREZ, D. O.; BONACCINI, J. A. Two Centuries of Kantian studies in Brazil. In: RAUSCHER, F. J.; PÉREZ, D.O. (Ed.). Kant in Brazil.

Rochester; Suffolk: University of Rochester Press, 2012. p. 14-25. (North American Kant Society Studies in Philosophy, v. 10).

PERIN, A. O problema da unidade da razão em Kant: uma reconstrução sistemática a partir de três momentos do desenvolvimento do período crítico. Porto Alegre: EDIPUCRS, 2008.

PORTA, M. A. González. Estudos Neokantianos. São Paulo: Loyola, 2011.

PORTELA, L. C. Yanzer. Por que a Crítica da razão pura é uma Metafísica? Ensaio de uma defesa. Dissertação (Mestrado em Filosofia) - Universidade Federal da Paraíba. João Pessoa, 2001. 
PRICHARD, H. A. Kant's theory of knowledge. Oxford: Clarendon Press, 1909.

RAUSCHER, F. J. Introduction. In: RAUSCHER, F. J.; PÉREZ, D.O. (Ed.). Kant in Brazil. Rochester; Suffolk: University of Rochester Press, 2012. p. 1-13. (North American Kant Society Studies in Philosophy, v. 10).

RAUSCHER, F. J.; PÉREZ, D.O. (Ed.). Kant in Brazil. Rochester; Suffolk: University of Rochester Press, 2012. (North American Kant Society Studies in Philosophy, v. 10).

REICH, K. Die Vollständigkeit der Kantischen Urteilstafel. Berlin: Schoetz, 1932. [The completeness of Kant's table of judgments. Transl. J. Kneller and M. Losonsky. Stanford; Calif: Stanford University Press, 1992. (Stanford Series in Philosophy: Studies in Kant and German idealism)].

SCHÖNRICH, G. Kategorien und transzendentale Argumentation: Kant und die Idee einer transzendentalen Semiotik. Frankfurt am-Main: Suhrkamp, 1981.

STERN, Robert. Transcendental arguments and skepticism. Oxford: Oxford University Press, 2000.

STRAWSON, P. F. Individuals: an essay in descriptive Metaphysics. London: Routledge, 1990 [1959].

STRAWSON, P. F. The bounds of sense: an essay on the Critique of Pure Reason. London: Methuen, 1966. Reimpr.: Routledge, 1999.

STROUD, Barry. Transcendental arguments, Journal of Philosophy, 65 1968.

TERRA, R. R. Passagens: estudos sobre a filosofia de Kant. Rio de Janeiro: UFRJ, 2003.

THISTED, M. A. The Janus Face of the boundary of pure reason concept: from the critique of dogmatic metaphysics to the foundation of a critical 
metaphysics. In: INTERNATIONALEN Kant- Kongresses zu São Paulo, 10. Recht und Frieden in der Philosophie Kants (Akten...). Berlin: W. de Gruyter, 2008. Bd. 2, p. 761-771.

VAN CLEVE, J. Problems from Kant. New York: Oxford University Press, 1999.

WALKER, R. Kant: the arguments of the philosopher's. Ed. Ted Honderich. London: Routledge \& Kegan, 1978.

WATKINS, E. Kant and the metaphysics of causality. Cambridge: Cambridge University Press, 2005.

WESTPHAL, K. Kant's Critique of Pure Reason and Analytic Philosophy. In: GUYER, P. (Ed.). The Cambridge companion to Kant. Cambridge: Cambridge University Press, 2010. p. 401-439.

WOHLERS, C. Kants Theorie der Einheit der Welt: eine Studie zum Verhältnis von Anschauungsformen, Kausalität und Teleologie bei Kant. Würzburg: Königshausen und Neumann, 2000.

WOLFF, M. Die Vollständigkeit der kantischen Urteilstafel. Mit einem Essay über Freges Begriffsschrift. Frankfurt am-Main: V. Klostermann, 1995.

WOLFF, R. P. Kant's theory of mental activity: a commentary on the Transcendental Analytic of the Critique of Pure Reason. Cambridge: Harvard University Press, 1963. 2. ed.: Gloucester: P. Smith, 1973.

WUNDT, M. Kant als Metaphysiker: ein Beitrag zur Geschichte der deutschen Philosophie im 18. Jahrhundert. Stuttgart: F. Enke, 1924.

YOUNG, M. Functions of thought and the synthesis of intuitions. In: GUYER, P. (Ed.). The Cambridge companion to Kant. Cambridge: Cambridge University Press, 1992. p. 101-122. 
* A revista Princípios agradece à revista Studia Kantiana a permissão para reeditar este último artigo de Juan Bonaccini publicado em vida. O original apareceu no número 20 daquele periódico, encontrando-se disponível em http://www.sociedadekant.org/studiakantiana/index.php/sk/article/view/24 $1 / 222$. 